\title{
Current research on head and neck cancer-associated long noncoding RNAs
}

\author{
Wei Song ${ }^{1}$, Yimin Sun ${ }^{1}$, Jie Lin ${ }^{2}$ and Xiaoqin $\mathbf{B i}^{3}$ \\ ${ }^{1}$ State Key Laboratory of Oral Diseases, West China School of Stomatology, Sichuan University, Chengdu, Sichuan 610041, \\ P.R. China \\ ${ }^{2}$ Department of Dental Anesthesiology, West China Hospital of Stomatology, State Key Laboratory of Oral Diseases, Sichuan \\ University, Chengdu, Sichuan 610041, P.R. China \\ ${ }^{3}$ Department of Head and Neck Oncology, West China Hospital of Stomatology, State Key Laboratory of Oral Diseases, \\ Sichuan University, Chengdu, Sichuan 610041, P.R. China
}

Correspondence to: Jie Lin, email: 13558852310@163.com

Xiaoqin Bi, email: hxbxq@163.com

Keywords: head and neck cancer; long noncoding RNA; cancer progression; clinical implication

Received: June 09, 2017 Accepted: September 08, $2017 \quad$ Published: November 22, 2017

Copyright: Song et al. This is an open-access article distributed under the terms of the Creative Commons Attribution License 3.0 (CC BY 3.0), which permits unrestricted use, distribution, and reproduction in any medium, provided the original author and source are credited.

\begin{abstract}
Head and neck cancers (HNC) are one of the ten leading cancers worldwide, including a range of malignant tumors arising from the upper neck. Due to the complex mechanisms of HNC and lack of effective biomarkers, the 5-year survival rate of HNC has been low and the mortality rate has been high in recent decades. Long noncoding RNAs (IncRNAs), noncoding RNAs longer than $\mathbf{2 0 0}$ bps, are a focus of current cancer research, closely related to tumor biology. LncRNAs have been revealed to be aberrantly expressed in various types of HNC, and the dysregulated IncRNAs participate in HNC progression and induce malignant behavior by modulating gene expression at diverse levels. This review will focus on the functions and molecular mechanisms of dysregulated IncRNAs in HNC tumorigenesis and progression, as well as their diagnostic, therapeutic or prognostic implications in HNC.
\end{abstract}

\section{INTRODUCTION}

Head and neck cancers (HNC) are one of the ten leading cancers worldwide originating from the upper neck, including the oral cavity, tongue, hypopharynx, nasopharynx, larynx, and thyroid [1-4]. More than $90 \%$ of the cancer cases of squamous origin, forms the most common histological subtype of $\mathrm{HNC}$, referred to as head and neck squamous cell carcinoma (HNSCC) [5]. Smoking, alcohol consumption are the most common incentives of HNSCC, and the human papillomavirus (HPV) infection also contributes to its occurrence [6-9].

Oral squamous cell carcinoma (OSCC) is the fourth most common cancer in the world, accounting for more than $90 \%$ of oral cancer $[10,11]$. Due to the consumption of alcohol, tobacco and areca chewing, males' incidence of OSCC is significantly higher than females' [10]. Laryngeal squamous cell carcinoma (LSCC), a malignant cancer arising from the upper respiratory tract, consists of more than $95 \%$ of laryngeal cancers [12]. LSCC mostly occurs in glottic $(60 \%)$ or supraglottic regions, and only $5 \%$ cases are subglottic [12]. Currently, the main methods for LSCC treatment include surgical intervention, radiotherapy and chemotherapy. Most of them may damage physiological functions like swallowing or speaking. Tongue squamous cell carcinoma (TSCC) is the major subtype of oral cancer with a high rate of proliferation and recurrence, and is famous for its aggressive, rapid local invasion and spread [13-15]. Hypopharyngeal squamous cell carcinoma (HSCC), a relatively rare type of $\mathrm{HNC}$, arises from mucosal lesions of the upper aerodigestive tract [16]. HSCC has rather dismal prognosis and the lowest survival rate compared with other types of HNSCC due to poor locoregional control and lack of obvious early symptoms [17-20]. Nasopharyngeal carcinoma (NPC) is a prevalent malignant tumor and particularly occurs in specific geographic localities including North Africa, Southeast Asia, and Southern China [21, 22]. NPC can be divided into 2 types (differentiated and undifferentiated NPC), and the primary histologic type is the latter [23]. Resulted from its anatomical position (near the skull) and the unobvious symptoms, the early diagnosis of NPC is 
so difficult that patients are mostly diagnosed in advanced and/or metastatic stages [24, 25]. Thyroid cancer (TC) is the most common endocrine cancer, which can be classified into two histological types according to variants in tumor origins. Tumors derived from follicular thyroid cells dominate thyroid carcinomas, including papillary thyroid cancer (PTC), follicular thyroid cancer (FTC), and anaplastic thyroid cancer (ATC). Parafollicular C cell-derived tumors only accounts for a small part of all the cases, among which medullary thyroid cancer (MTC) takes up the majority. PTC and FTC form the type known as differentiated thyroid cancer (DTC), while MTC and ATC are collectively classified as poorly differentiated thyroid cancer (PDTC) [26, 27].

The initiation and progression of $\mathrm{HNC}$ is a rather complex multistep process involving genetic and epigenetic changes and dynamic alternations in the genome. Both the complex mechanisms of HNC and the lack of effective biomarkers contribute to dismal prognosis. Thus, there is a compelling need to elucidate the mechanisms of HNC and explore predictive biomarkers so that cancers can be diagnosed early and patients can be provided with efficient therapeutic strategies [28-30].

Previously, noncoding RNAs (ncRNAs) were widely regarded as the "junk" or "noise" of genetic transcription since ncRNAs lack protein-coding potential; but in recent years, with the development of DNA sequencing technologies, ncRNAs are reported to participate in regulating expression of coding genes during the whole gene expression process [31]. According to the size of the transcript, non-coding RNAs are categorized into two groups: short ncRNAs $(<200 \mathrm{nt})$ and long ncRNAs (lncRNAs) ( $>200 \mathrm{nt}$ ). LncRNAs are generally located in the nucleus, with their expression patterns highly tissue-specific $[32,33]$. LncRNAs are a focus of current cancer research, closely related to tumor biology. Experimental results have demonstrated that a growing number of lncRNAs are found dysregulated in HNC and some can be the driving force of malignant transformation via regulating $\mathrm{HNC}$ cell viability and motility [34, 35]. Aberrantly expressed lncRNAs contribute to multiple biological processes such as cellular growth, proliferation and differentiation, apoptosis, and tumorigenesis by modulating gene expression at epigenetic, transcriptional, post-transcriptional, translational and post-translational levels [35-37].

Aside from those well-known HNC-associated lncRNAs, the expression and functions of numerous lncRNAs in HNC are still elusive. Some lncRNAs have been found to play pivotal roles in HNC initiation and progression, suggesting they might function as novel biomarkers and therapeutic targets to provide more effective diagnosis, prognosis and treatment for $\mathrm{HNC}$ patients $[35,38]$. Therefore, in the review we outline the extensively studied lncRNAs and several recently discovered HNC-related lncRNAs, and try to elaborate the role they play in $\mathrm{HNC}$ along with the mechanisms of HNC pathogenesis.

\section{The IncRNAs extensively associated with HNC}

Previously, long noncoding RNAs in head and neck cancers have been extensively studied. The expression levels of lncRNAs in cancer cells are related to different stages of cancer and cancer progression. Here, we classify lncRNA according to different tumor types, including HNSCC, NPC, TC, TSCC, OSCC and LSCC, and the effects of tumor-associated lncRNAs and their corresponding downstream molecules on the tumor are described respectively.

\section{HNSCC-associated IncRNAs}

\section{HOTAIR}

LncRNA HOX transcript antisense RNA (HOTAIR), with a full-length sequence of $2.2 \mathrm{~kb}$, is transcribed from the antisense strand of HOXC gene cluster on chromosome 12. Mounting evidence has revealed that HOTAIR, as a key epigenetic regulator, plays a pivotal role in initiation and progression of human malignant tumors, like esophageal squamous cell carcinoma, colorectal cancer and pancreatic cancer [39-41]. Also, the expression level of HOTAIR has been found significantly increased in $\mathrm{HNC}$ tissues than in paired adjacent non-tumor tissues.

Research has suggested a correlation between the aberrant expression of HOTAIR and cell viability. HOTAIR depletion can lead to cancer cell apoptosis in vitro, and decelerate tumor growth via activating mitochondrial-related cell death pathway in HNSCC both in vitro and in vivo [42]. Previous research has verified that the network consisting of lncRNAs, RNA binding proteins (RBPs) and miRNAs has tremendous implications during the HNSCC progression. There is a feed-forward regulatory loop between HOTAIR and HuR [43], an RBP participating in the post-transcriptional regulation of target genes [44]. HOTAIR could increase HuR expression via acting as a competing endogenous RNA (ceRNA) of miR7. Conversely, HuR could enhance the sponge activity of HOTAIR and up-regulate it through miRNA recruitment [43]. Both HOTAIR and HuR are over-expressed in HNSCC, associated with the promotion of cell viability, metastasis and invasion [43].

\section{H19}

LncRNA H19, transcribed from chromosome $11 \mathrm{p} 15.5$, is becoming a hotspot in cancer research and is mainly located in cytoplasm. The H19 gene is abundantly expressed in mesoderm- and endoderm-derived tissues at embryonic stage, while it is not expressed in most parts of the body except cardiac and skeletal muscle after birth and is re-expressed in the tumor tissues $[45,46]$. H19 expression is directly induced by c-myc in various cancers $[47,48]$. 
H19 and Insulin-like growth factor 2 (IGF2), the adjacent reciprocal imprinted genes in the same locus, are expressed from the maternal and paternal allele, respectively. Loss of imprinting (LOI) at the $\mathrm{H} 19$ and IGF2 locus has been manifested to constitute a novel oncogenic mechanism of HNC. IGF2 and H19 were imprinted in all the normal squamous epithelium of 49 HNSCC samples examined (77\% of 64 samples), while 12 of 32 samples(37.5\%) confirmed LOI at the H19 gene and 11 of 27 samples $(40.7 \%)$ proved LOI at the IGF2 gene [49]. Furthermore, the IGF2/H19 imprinting changes were correlated with juvenile nasopharyngeal angiofibroma (JNA). IGF2 overexpression was observed in 8 out of 22 cases $(36.4 \%)$ and 7 out of 19 cases (36.8\%) showed H19 overexpression [50]. Accumulating evidence has shown that lncRNA H19 is up-regulated in various human malignant tumors. $\mathrm{H} 19$ and its mature product miR-675 are significantly over-expressed in HNSCC, leading to higher invasive capability, worse overall survival (OS) and higher risk of tumor recurrence [51].

\section{HNGA1}

Aerobic glycolysis, a common inducement of cancer malignancy, has been recently reported to play a significant role in tumorigenesis and tumor development in HNSCC. A novel lncRNA, HNSCC glycolysisassociated 1 (HNGA1), has been found associated with HNSCC glycolysis and can regulate cell proliferation in HNSCC [52]. The expression of HNGA1 is significantly up-regulated while miR-375 is down-regulated in tumor tissues. Both of them are related to glycolysis: overexpression of HNGA1 promoted glycolysis in tumor tissues, whereas the ectopic expression of miR-375 has the opposite effect [52]. Moreover, their expressions in tumor tissues show a certain correlation, suggesting that there might be a specific mechanism of their joint regulation in the occurrence and development of HNSCC [52]. Previous research has revealed the role of SCL2A1, one of the gene encoding a major glucose transporter in the plasma membrane, in the HNSCC progression. Highly expressed miR-375 can directly inhibit the expression of SCL2A1 by binding to its 3'-UTR region, which has an inhibitory effect on tumor cell glycolysis and thereby inhibits cell proliferation. HNGA1 might serve as an endogenous "sponge" by competing for miR-375 binding site to eliminate the inhibitory effect of miR-375 on SCL2A1 expression and promote cell proliferation in HNSCC cells [52]. Similar mechanism has been reported in their other studies, and lncRNA-p23154 can modulate the glycolysis and proliferation of OSCC via repressing miR-375 expression [53].

\section{PTENP1}

PTENP1, a conserved pseudogene of PTEN located on chromosome band $9 \mathrm{p} 21$, is highly homologous to its ancestral gene PTEN [54]. Accumulating evidence has revealed that the expression levels of PTENP1 and
PTEN are positively correlated, and both are significantly down-regulated in HNSCC cell lines compared with adjacent non-tumor cells [55]. The decreased PTENP1 expression in multiple cancers is mainly resulted from two reasons: PTENP1 promoter methylation and copy number reduction of genomic PTENP1. In HNSCC cell lines, 4 of 5 cell lines $(80 \%)$ has been observed copy number reduction (completely or partially) in the PTENP1 locus, suggesting copy number alterations play a pivotal role in PTENP1 expression [55]. Ectopically expressed PTENP1 decelerates cell growth, colony formation, metastasis and invasion, and thus attenuates HNSCC tumorigenesis [55].

\section{PANCR}

PANCR is a lncRNA adjacent to the PITX2 gene which was first found in cardiomyocytes regulating the expression of splice variant PITX2C [56]. PITX2 is a homeobox gene located on chromosome 4q25 and encodes four isoforms (PITX2A, PITX2B, PITX2C, PITX2D) that are involved in the development of the structure prior to transcription [57]. In prostate cancer, hypermethylation of PITX2 is associated with a significant risk of disease progression $[58,59]$. In contrast, the overexpression of hypomethylation of PITX2 may lead to tumor progression in ovarian and thyroid cancers [60]. The samples showed PITX2 methylation, whereas PANCR was found highly methylated in HNSCC tissues [61]. In HNSCC, PITX2 hypermethylation leads to a reduction in incidence, whereas PANCR hypermethylation is related to a higher risk of death in patients [61]. Additionally, high PITX2 methylation was related to $\mathrm{p} 16$ expression and prolonged survival in patients with p16 positive and PITX2 hypermethylation in HNSCC [61].

\section{Application}

HNSCC ranked the sixth among the most common cancers with only $40 \%$ five-year-survival and nearly $60 \%$ mortality within five years because of high metastases and recurrences [62]. Research has focused on therapies, and lncRNAs can be promising strategies to inhibit cancer progression. The known mechanisms of HNSCCrelated lncRNAs are shown in Figure 1. The knockdown of HOTAIR, H19/miR-675 and HNGA1 leads to poor proliferation, migration and invasion [42, 43, 51, 52], and overexpression of PTENP1 could inhibit cell proliferation, invasion and colony formation [55]. Individually, HOTAIR depletion induces mitochondrial calcium uptake 1-dependent cell death [43].

LncRNAs can also be adapted to diagnosis and prognosis of HNSCC. Higher expression levels of HOTAIR, H19, HNGA1 are observed in HNSCC compared with normal tissues $[43,51,52]$, while PTENP1 is down-regulated [55], which is believed to be promising biomarkers for diagnosis besides conventional diagnostic method. To inhibit tumor growth and migration, the expression levels of specific lncRNAs are adjusted to the opposite sides, and the alterations achieve willing effect. 
For prognosis, highly expressed HOTAIR, H19 and HNGA1 or down-regulated PTENP1 are risky factors. Patients with high expression of HOTAIR, H19 or low expression of PTENP1 have poorer OS and disease-free survival (DFS) [43, 51, 52, 55, 63]. Highly expressed HOTAIR is correlated with tumor size and lymph node metastasis [43], while H19 can contribute to higher patient relapse [51, 63]. HNGA1 is correlated with post-operative survival [52]. Besides, the methylation status of PITX2 gene and its adjacent lncRNA PANCR are convinced to be effective predictors for OS [61].

\section{NPC-associated IncRNAs}

\section{HOTAIR}

HOTAIR expression is significantly increased in NPC tissues $[64,65]$. In invasive NPC cell lines, the expression level of HOTAIR is up-regulated compared with that in high-differentiated cell lines [64]. HOTAIR can facilitate NPC tumorigenesis by functioning as an angiogenic inducer and promoting cell proliferation through direct and indirect signaling pathways: activating vascular endothelial growth factor-A (VEGFA) transcription by directly targeting its promoter, or up-regulating VEGFA and Ang2 by increasing glucose-regulated protein 78 (GRP78) expression [65]. Knockdown of HOTAIR leads to inhibition of cell proliferation, migration and invasion as well as stimulation of cell apoptosis [65].

\section{H19}

H19 upregulation was observed in the poordifferentiated NPC cell line compared with the normal nasopharyngeal epithelial cell line [66]. Hypermethylation of the $\mathrm{CpG}$ locus in the $\mathrm{H} 19$ promoter region can lead to the imbalance of H19 gene expression, suggesting that hypermethylation of the gene promoter region may involve in the differentiation of human NPC cells and transcriptional silencing of imprinted genes [66]. Furthermore, H19 inhibits E-cadherin expression, induces Epithelial-Mesenchymal Transition (EMT), and promotes invasion in NPC by modulating the miR-630/ enhancer of zeste homolog 2 (EZH2) axis [67]. EZH2, a downstream target of miR-630, can be down-regulated by miR-630. The elevated H19 represses the activity of miR-630, thus increasing EZH2 expression. EZH2 accumulation induces the silence of epigenetic target genes, and promotes cell invasion [67].

\section{MALAT1}

Metastasis-associated lung adenocarcinoma transcript 1 (MALAT1), a long non-coding RNA transcribed from gene locus on chromosome 11q13, is reported to be associated with a variety of human tumors, such as lung, gastric and bladder cancer [68-70]. Recently, emerging evidence has demonstrated that aberrantly expressed MALAT1 involves in the tumorigenesis and tumor progression in HNC. MALAT1 accumulation can enhance proliferative capacity, metastatic and invasive potential, as well as induce apoptosis in the most common types of HNC, like thyroid carcinoma, NPC, LSCC, TSCC and OSCC [71-79]. MALAT1 is up-regulated in NPC. Several studies have elaborated on the correlation and the possible interactive molecular mechanisms between MALAT1 and HNC. Two molecular effects of MALAT1, either regulating alternative splicing or transcription, have been uncovered based on a sequence of experiments [80].

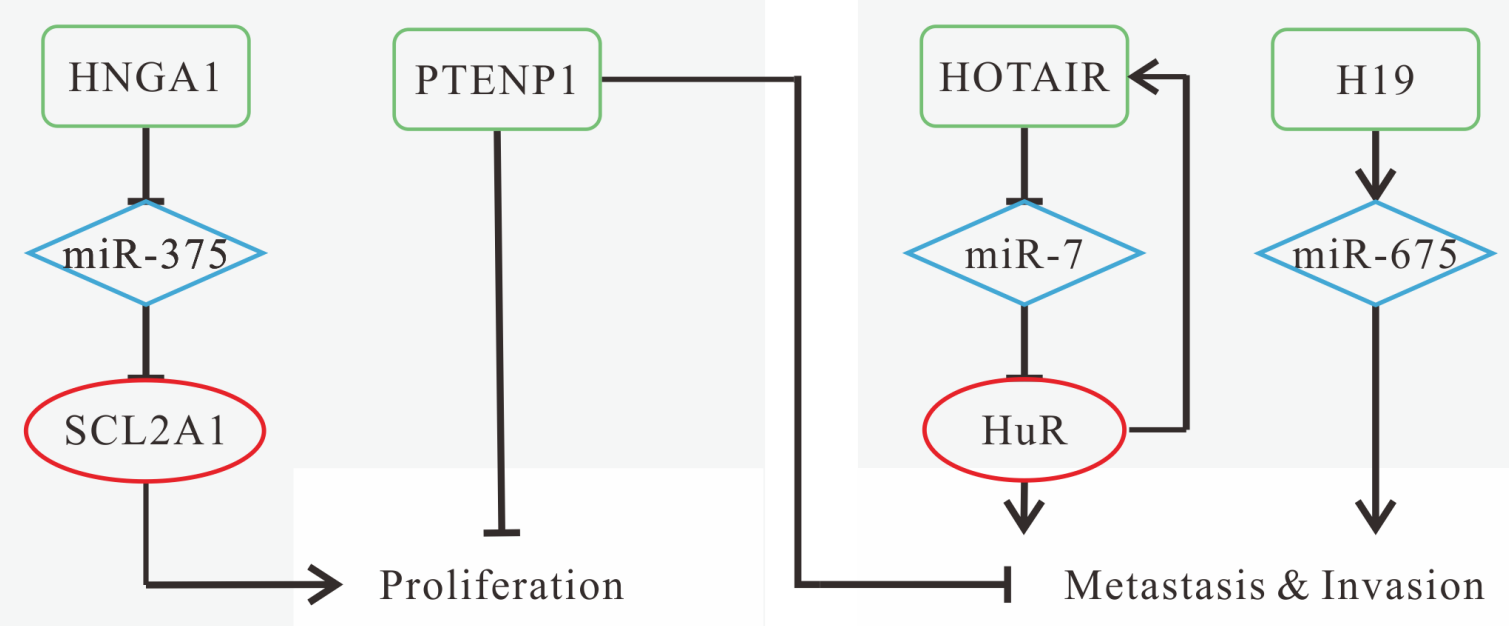

Figure 1: Mechanisms of IncRNAs in HNSCC progression. (A) HNGA1 promotes cell proliferation and glycolysis by acting as a ceRNA of miR-375 to increase SCL2A1 levels; (B) down-regulated PTENP1 promotes growth, proliferation, colony formation, migration and invasion; (C) HOTAIR promotes metastasis by forming a feed-forward regulatory loop with HuR; (D) H19 promotes cell viability, migration and invasion by miR-675 (the mature product of H19) overexpression. 
MALAT1, as a ceRNA, promotes radioresistance of NPC cells via modulating miR-1/slug axis [72]. MALAT1induced downregulation of miR-1 elevates Slug protein, a downstream target of miR-1, and then increases cancer stem cell (CSC) activity and radioresistance of NPC cells. Over-expressed miR-1 can decrease MALAT1 expression in turn, indicating that there might be a reciprocal repression loop between MALAT1 and miR-1 [72].

Collectively, MALAT1 might serve as a promising diagnostic, prognostic biomarker and therapeutic target for HNC patients. We infer that resveratrol, which is of potential use in prevention and treatment of colorectal cancer [81], might also have the same anti-tumor effect on HNC through the inhibition of Wnt/ $\beta$-catenin signaling pathway.

\section{ANRIL}

ANRIL (antisense noncoding RNA in the INK4 locus), is a long noncoding RNA spanning $126.3 \mathrm{~kb}$ at the antisense orientation of the INK4B-ARF-INK4A gene cluster, whose spliced product is a $3834 \mathrm{bp}$ RNA consisting of 19 exons. ANRIL has been reported to be related to epigenetic transcriptional repression of the INK4 locus through the interactions between Chromobox 7 (CBX7) and ANRIL [82]. Accumulating evidence has proved that ANRIL has the oncogenic ability to induce NPC. Highly expressed ANRIL could enhance cell proliferative and transforming capacity, as well as increase the proportion of side population cells (SP cells) in NPC [83]. ANRIL could also reprogram glucose metabolism for energy provision of cell proliferation. ANRIL-mediated up-regulation of Glut1 and LDHA, associated with the regulation of basal uptake of glucose and aerobic glycolysis, respectively, can enhance glucose uptake for rapid ATP production in NPC cells. We infer that ANRIL might activate the mTOR signal pathway via promoting the phosphorylation of Akt, and thus influences the expression of essential genes in glycolysis [83]. Additionally, miRNA let-7a is down-regulated in NPC tissues and negatively correlated with ANRIL expression. ANRIL knockdown might reduce carcinogenic ability and increase DDP-induced cytotoxicity by increasing miR-let7 a expression in NPC [84].

\section{ROR}

LncRNA-ROR, consisting of four exons, is located at chromosome $18 \mathrm{q} 21.31$ [85]. As a regulatory molecule, increasing evidence has presented that lncRNA-ROR is associated with tumorigenesis, progression and metastasis in multiple tumors. A recent study has reported lncRNAROR is significantly up-regulated in human NPC tissues [86]. Overexpressed lncRNA-ROR decreases the apoptosis rate and promotes cell proliferation. LncRNA-ROR can promote cell metastatic and invasive ability by inducing an EMT phenotype in NPC cells, indicating that ROR may serve as an oncogene [86]. Moreover, the regulation of p53 and p21 at the translational level after chemotherapy also contributes to chemoresistance. Highly expressed IncRNA-ROR may enhance the chemotherapy resistance ability of NPC cells by inhibiting the p53 pathway [86].

Previous research has demonstrated that EMT of tumor cells not only increases migration, but also leads to drug resistance [87]. Down-regulated lncRNA-ROR in breast cancer cells can inhibit the EMT process and cell invasion, and increase the sensibility to tamoxifen [88]. Based on these findings, we infer that lncRNAROR does play a critical role in NPC progression. Further investigation is required to explore the specific mechanisms about how lncRNA-ROR contributes to NPC migration and chemotherapy resistance.

\section{AFAP1-AS1}

Actin filament associated protein 1 antisense RNA1 (AFAP1-AS1), has been confirmed to be associated with metastasis and poor prognosis of NPC in recent years [89]. AFAP1-AS1 affects the expression of cytoskeletally-regulated proteins via inhibiting the Rho/Rac signaling pathway in NPC. Knockdown of AFAP1-AS1 significantly increases expression of small GTPases such as Rhogdi, Pfn1, Rab10, Rab11a, Rac2 and RhoA in the pathway while decreases RhoC, Rab11b and Lasp1 proteins. Furthermore, AFAP1-AS1 can promote NPC cell migration by regulating the integrity of actin filament [89]. The same molecular mechanism has been observed in lung cancer [90] and hepatocellular carcinoma [91].

\section{LET}

The expression level of lncRNA-LET has been found significantly lower in NPC tissues than in paired normal tissues, and the down-regulated LET is related to larger tumor size and poor prognosis of NPC patients. In vivo experiment shows that enhanced LET expression inhibits cell proliferation and induces cell apoptosis by up-regulating the expression level of cleaved Caspase-3. The attenuated LET expression is induced by EZH2-mediated H3K27 histone methylation in the LET promoter region. Elevated LET expression represses cell proliferation and induces apoptosis of NPC cells, while knockdown of LET could reverse the effects [92]. Collectively, the inverse correlation between the expression of IncRNA-LET and EZH2 may provide a potential therapeutic method for NPC treatment.

\section{LINC0086}

LncRNA LINC0086 is found down-regulated in serum samples and tissues of NPC patients, and the Kaplan-Meier survival curve shows that the expression level of LINC0086 is positively correlated with the survival rate of NPC patients. MiR-214 is widely recognized as an oncogene in malignant tumors, and miR-214 expression could be reduced through directly interacting with LINC0086. Based on these discoveries, it is suggested that overexpression of LINC0086 could inhibit cell proliferation and promote apoptosis in NPC through the repression of miR-214 expression. Interestingly, the inhibitory effects of LINC0086 on NPC cells could also be reversed by miR-214 overexpression [93]. 


\section{LOC401317}

LncRNA LOC401317 expression has been reported significantly up-regulated along with TP53 overexpression in NPC cell line HNE2, and LOC401317 is directly modulated by $\mathrm{p} 53$ at the transcriptional level. Overexpression of LOC401317 triggers HNE2 cell cycle arrest at the G0/G1 phase, as well as increases the apoptosis rate. Interestingly, LOC401317 doesn't form a feedback loop with either p53 or MDM2, and LOC401317 expression has no effect on them. LOC401317 alters the expression levels of several key effector molecules of cell cycle progression and apoptosis. Elevated expression of LOC401317 might result in the trigger of cell cycle arrest through increased p21 and decreased cyclin D1 and E1, as well as the promotion of cell apoptosis by activating poly (ADP-ribose) polymerase (PARP) and caspase 3 [94].

\section{Application}

NPC is a group of malignant lesions, the symptoms of which vary from non-specific ones to cranial nerve palsies [1]. The incidence of NPC has gradually decreased over the past few decades. However, the early diagnosis and treatment strategies remain to be improved [95].

In NPC tissues, HOTAIR, H19, MALAT1, ANRIL, ROR and AFAP1-AS1 are up-regulated [64, 67, 72, 83, 86, 89], while LET, LINC0086, LOC401317 and LINC00312 are down-regulated [92-94, 96], which is correlated with their applications in treatment and prognosis. Both knockdown of HOTAIR, H19, MALAT1, ANRIL, ROR and AFAP1-AS1, and overexpression of LET, LINC0086 and LINC00312 may have inhibitory effects on cell viability, migration and invasion $[64,65,67,84,86$, 89, 92-94, 97]. Moreover, knockdown of MALAT1 can increase radiation sensitivity [78]. The inhibition of ROR expression can reduce chemotherapy resistance [86].

For prognosis, highly expressed HOTAIR is the indication of poor local recurrence-free survival, OS and DFS [64]. High expression of MALAT1 causes poor overall survival [72], while high expression of ANRIL has longer OS and shorter DFS [83]. Highly expressed AFAP1-AS is correlated with distant tumor metastasis, and indicates poorer OS and relapse-free survival [89]. Downregulated LET is correlated with tumor size and poorer prognosis [92]. LINC0086 and LINC00312 expression levels are associated with lymph node metastasis, and patients with higher expression are predicted to have a higher survival rate $[93,96]$. The known mechanisms of NPC-related lncRNAs are shown in Figure 2.

\section{TC-associated IncRNAs}

\section{BANCR}

Recently, studies have found a novel lncRNA, BRAF-activated non-coding RNA (BANCR), is upregulated in PTC tissues and PTC IHH-4 cells compared with adjacent normal tissues [98, 99]. The reduced expression of BANCR in IHH-4 cells can significantly inhibit cell proliferation and induce apoptosis, but has no effect on cell migration [98]. Enhanced BANCR expression in PTC may promote cell proliferation by decreasing the percentage of cells in G1 phase, and inhibit apoptosis through activation of autophagy [98]. Furthermore, knockdown of BANCR inhibits tumor cell growth and induces cell cycle arrest at $\mathrm{G} 0 / \mathrm{G} 1$ phase through the reduction of cyclin D1 [99]. Highly expressed BANCR may increase the expression level of thyroid-stimulating hormone receptor (TSHR) via increasing EZH2 recruitment in PTC, which may be one of the possible mechanisms that BANCR contributes to PTC [99].

Interestingly, BANCR can serve as either a carcinogenic factor or a tumor suppressor, and several studies have reported completely different results from the above findings. The expression of BANCR has been found down-regulated in PTC tissues and PTC cell lines (TPC-1, $\mathrm{K} 1$, and BCPAP) [100]. And upregulation of BANCR in $\mathrm{K} 1$ cell lines inhibits cell proliferation and invasion, as well as induces apoptosis [100]. BANCR plays a significant role in inactivation of the MAPK pathway in tumors, such as malignant melanoma [101] and lung cancer [102]. Highly expressed BANCR can affect MAPK pathway by reducing the expression levels of phosphorylated ERK and phosphorylated p38 in K1 cell lines [100].

Collectively, BANCR expression level differs from PTC cell lines. Highly expressed BANCR can promote the PTC development by modulating cell cycle, autophagy activation or the expression level of TSHR, while downregulated BANCR can exert its effect by affecting the MAPK pathway. We suggest that there might be other unknown factors involved in regulating the expression level of BANCR in PTC, and the specific mechanisms require further investigation.

\section{PTCSC}

Recently, a class of long intergenic noncoding RNAs named papillary thyroid cancer susceptibility candidate (PTCSC), such as PTCSC1 (located in 8q24), PTCSC2 (located in 9q22) and PTCSC3 (located in 14q13), might predispose infected persons to thyroid cancer. The expression levels of PTCSC2 and PTCSC3 are strictly thyroid-specific, and they may serve as promising tumor suppressors [103, 104].

PTCSC2 is significantly down-regulated in PTC tissues compared with paired normal tissues [103]. PTCSC2 may enrich the expression of other genes involved in cell cycle and cancer progression. Significant correlation was observed between the risk allele [A] of single nucleotide polymorphism (SNP) rs965513 and the low expression levels of PTCSC2, FOXE1, and TSHR in non-tumor thyroid tissues along with high PTC risk, suggesting that there might exist a multilayer regulatory network. Additionally, the 5' end of PTCSC2 (isoform c) overlaps the promoter region of FOXE1. Myosin-9 
(MYH9), as a binding protein of PTCSC2, can regulate the transcription of FOXE1 and PTCSC2 via inhibiting the activity of FOXE1-and-PTCSC2-shared promoter, while PTCSC2 overexpression can reverse MYH9-induced promoter inhibition [105].

PTCSC3 expression is also significantly decreased in PTC tissues, and SNP rs944289 risk allele [T] is related to the downregulation of PTCSC3. SNP rs944289 overlaps the binding site for CCAAT/enhancer binding protein $(\mathrm{C} / \mathrm{EBP}) \alpha$ and $\beta$, and either $\mathrm{C} / \mathrm{EBP} \alpha$ or $\mathrm{C} / \mathrm{EBP} \beta$ can activate the PTCSC 3 promoter. PTCSC3 can influence the expression of genes associated with DNA replication, recombination and repair, tumor cell viability and motility and tumor morphology [104]. Moreover, PTCSC3 inhibits cell growth, promotes apoptosis and arrests cell cycle at G1/S and G2/M phases in thyroid cancer [106]. Overexpression of PTCSC3 can reduce the expression of miR-574-5p by acting as a ceRNA for miR-574-5p in different thyroid cancer types (of papillary, follicular and anaplastic origin) [106]. These findings suggest that PTCSC3 might regulate cell growth and apoptosis by targeting miR-574-5p.

Generally, the risk allele may involve in the reduction of PTCSC2 and PTCSC3 expression and the increased risk of thyroid cancer. Both PTCSC2 and PTCSC3 can play an important anti-tumor role by affecting the expression levels of other genes in thyroid cancer, but the specific mechanisms require further investigation.

\section{PVT1}

LncRNA PVT1 is transcribed from a gene located on chromosome 8q24, and the transcription can be regulated by Myc [107]. LncRNA PVT1 has been found significantly up-regulated in thyroid tissues. PVT1 silencing can repress proliferation, induce G0/G1 cell cycle arrest and decrease the expression of cell cyclerelated protein cyclin D1 and TSHR expressions at mRNA and protein levels in three kinds of TC cell lines IHH-4 (PTC), FTC-133 (FTC), and 8505C (ATC) [108]. Moreover, PVT1 knockdown reduces EZH2 recruitment. Silencing of PVT1 may down-regulate TSHR by binding to $\mathrm{EZH} 2$, and lead to proliferative inhibition in TC cells which are mediated by the interactions between TSH and TSHR. In all, the interactions between PVT1 and EZH2 present the oncogenic ability in TC progression [108].

\section{NEAT1}

LncRNA Nuclear Enriched Abundant Transcript 1 (NEAT1), also named as Nuclear Paraspeckle Assembly Transcript 1, is transcribed from the multiple endocrine neoplasia locus on chromosome 11, and it is confirmed to play a crucial role in the structure of paraspeckles [109, 110]. Previous research has revealed NEAT1 is associated with multiple human cancers, including prostate cancer, hepatocellular carcinoma, glioma and acute promyelocytic leukemia cells [111-114].

NEAT1 and Arg-1 are highly expressed in PTC while miR-214 is down-regulated, which promotes the development and progression of PTC [115]. NEAT1 down-regulates miR-214, and then increases the expression of $\beta$-catenin and promotes PTC malignant behaviors like migration and invasion [115]. Based on the reciprocal repression correlation between NEAT1 and miR-214, we can infer that upregulation of miR-214 might inhibit PTC malignant progression through the reduction of NEAT1 expression, offering a promising option for PTC treatment.
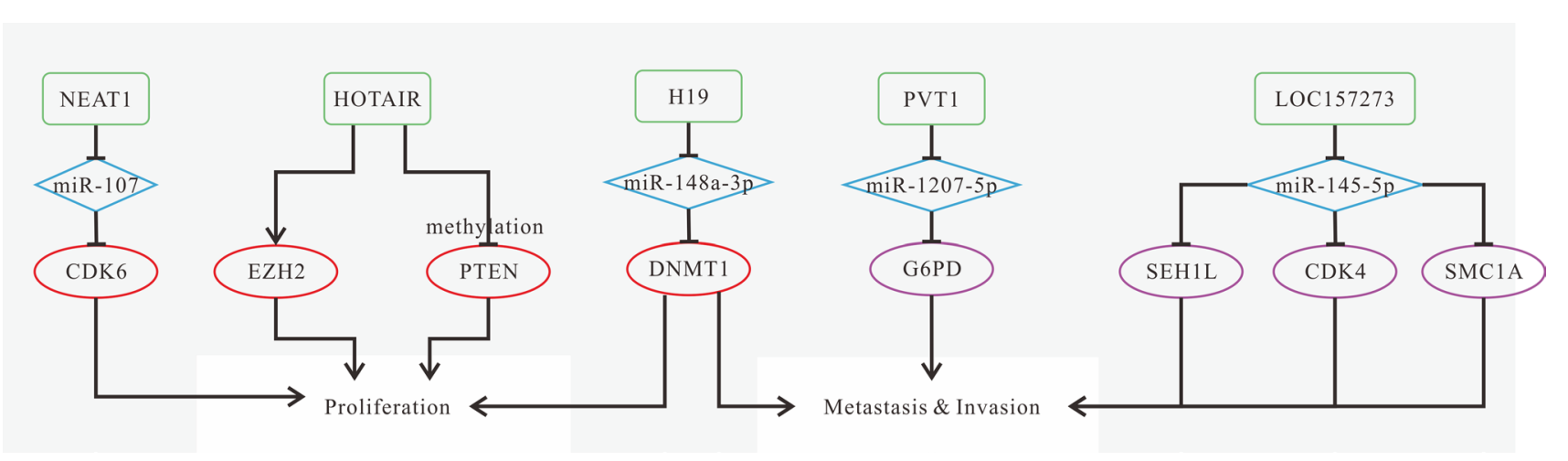

Figure 2: Mechanisms of IncRNAs in NPC progression. (A) HOTAIR promotes cell growth and angiogenesis by inducing VEGFA expression directly or indirectly; (B) MALAT1 promotes cancer stem cell activity and induces radioresistance to up-regulate slug by reducing miR-1 activity; (C) ANRIL enhances the proliferative and transforming capacity, reprograms cell glucose metabolism and induces SP cells possibly through activation of the mTOR signal pathway; d. low LET expression is induced by EZH2-mediated H3K27 histone methylation in the LET promoter region; (D) down-regulated LINC0086 promotes proliferation and inhibits apoptosis by decreasing the expression of miR-214; (E) down-regulated lncRNA LOC401317 promotes NPC cell cycle progression by down-regulating p21 and upregulating cyclin D1 and E1, as well as inhibits apoptosis by inhibiting PARP and caspase 3; (F) ROR promotes metastasis and invasion by inducing EMT; $(\mathbf{G}) \mathrm{H} 19$ induces EMT and promotes migration and invasion via modulating the miR-630/EZH2 axis; (H) AFAP1-AS1 promotes metastasis by increasing expression of AFAP1 and some cytoskeleton-regulated proteins. 


\section{FAL1}

Focally amplified IncRNA on chromosome 1 (FAL1), is transcribed from a focal amplicon on chromosome 1q21.2. Previous research has revealed that FAL1 can reduce the expression of cyclin-dependent kinase inhibitor 1A (CDKN1A, p21) via binding to the BMI1 proto-oncogene (BMI1), thus increasing cyclindependent kinase (CDK) activity, phosphorylating retinoblastoma protein $(\mathrm{RB})$, inducing E2F transactivation, and finally promoting the G1/S transition [116]. However, p21 mRNA expression is increased in PTC, contrary to the decrease in other cancers, indicating that $\mathrm{p} 21$ expression is not correlated with FAL1's in PTC. Also, FAL1 overexpression in PTC can lead to a significant increase in cyclin D1, E2F1, E2F2 and VEGF-A, suggesting FAL1 plays an oncogenic role in promoting proliferation and generating aggressive behavior such as multifocality in PTC [117].

\section{GAS8-AS1}

LncRNA growth arrest-specific 8-antisense RNA 1 (GAS8-AS1) has been identified as the secondary most frequently mutated gene (9.2\%), supported by the analysis of 402 Chinese PTC samples. LncRNA GAS8AS1 is down-regulated in PTC tissues compared with paired non-tumor tissues. Ectopic expression of both wild-type and mutated lncRNA GAS8-AS1 in PTC cell lines can inhibit cell viability, and the wild-type shows a more remarkable inhibitory effect than the mutated one. Among the 8 patients of 91 PTC cases with GAS8AS1 somatic mutations, seven were found to carry a c. $713 \mathrm{~A}>\mathrm{G} / 714 \mathrm{~T}>\mathrm{C}$ dinucleotide substitution, which might contribute to a higher rate of dismal prognosis [118]. Based on the findings, lncRNA GAS8-AS1 might function as a tumor suppressor, as well as a potential diagnostic and therapeutic target.

\section{NAMA}

BRAF mutation is one of the most common genetic alterations in PTC, and it is closely related to PTC development by influencing the MAP kinase signaling pathway. It has been reported a new lncRNA, noncoding RNA associated with mitogen-activated protein kinase pathway and growth arrest (NAMA), is down-regulated in PTC $[99,119]$. The reduction of BRAF expression, inactivation of MAP pathway or DNA damage could trigger NAMA expression, and then induce cell cycle arrest [119]. Each of these 3 alterations can activate Raf/ MEK/ERK signaling pathway in PTC, which is related to cell growth, proliferation and differentiation [119, 120]. Recent studies have demonstrated that there is no statistically significant difference between NAMA and TSHR expression in PTC [99]. NAMA is a promising target for future PTC treatment, but further research is needed to reveal the specific mechanisms of its function.

\section{HOTAIR}

HOTAIR was significantly up-regulated in TC compared with adjacent tissues. The results were similar to those detected in TC patients' plasma, whereas there was almost no HOTAIR expression in the plasma of the healthy volunteers [121]. HOTAIR susceptibility SNP rs920778 genetic variants (such as TT, TC and CC genotype) are significantly associated with PTC initiation via engaging in the regulation of HOTAIR expression. Subjects with the TT or CT genotype have higher HOTAIR RNA levels in non-tumor tissues and also higher risk of PTC developing than those with the CC genotype [122].

\section{MALAT1}

MALAT1 has been reported highly expressed in both non-cancerous thyroid tissues and PTC tissues, with increasing expression during PTC progression, whereas it is down-regulated in ATCs and PDTCs [71]. EMT is now identified as a process related to cell migratory and invasive properties, with the loss of cell polarity and adhesion. TGF- $\beta$-induced EMT can increase MALAT1 expression in PTC, suggesting it might also involve in the pathogenesis of thyroid malignancies [71]. IQ motif containing GTPase activating protein 1 (IQGAP1), is a scaffold protein involving in cellular processes via binding to cell adhesion, cytoskeletal and signal transduction proteins, like Rac1 and Cdc42. It has also been revealed that enhanced MALAT1 promotes cell proliferation and invasion in FTC by increasing IQGAP1 expression, while IQGAP1 knockdown can reverse the effect of MALAT1 [76].

\section{Application}

According to a survey in the United States, after years of research, the diagnosis of TC has increased a lot, but the morality of TC remains stable [123]. Papillary thyroid cancer, the most common type of TC, has shown a sharp rise in incidence [124]. Besides, TC is difficult to recognize, and more specific methods need to be investigated.

Previous research has found that the expression levels of FAL1, HOTAIR, LOC100507661, NEAT1, NONHSAT076754 are increased [117, 122, 125-127], while GASS-AS1, NAMA, NONHSAT037832 are decreased in tumor tissues $[118,119,128]$, which could be indicators for diagnosis. The known mechanisms of TC-related lncRNAs are shown in Figure 3. Knockdown or depletion of HOTAIR, LOC100507661, NEAT1 as well as overexpression of NAMA can inhibit tumor progression $[119,122,126,127]$. Knockdown of NONHSAT076754 can put an inhibitory effect on cell invasion and lymph node metastasis [125]. These findings suggest promising therapeutic strategies for TC patients. FAL1, NONHSAT037832 and NONHSAT076754 could be biomarkers for prognosis [117, 125, 128]. Highly expressed FAL1 increases the risk of multifocality [117]. NONHSAT037832 and NONHSAT076754 are associated 
with lymph node metastasis [125, 128]. Interestingly, BANCR expression exhibits an opposite trend according to different PTC cell lines. It is up-regulated in PTC cell line IHH-4 [98, 99], while down-regulated in cell lines TOC-1, K1 and BCPAP [100].

\section{TSCC-associated IncRNAs}

\section{MALAT1}

Additionally, it is verified that the interaction between MALAT1 and miR-124 also plays a critical part in tongue cancer cell growth [73], and miR-124 has been previously confirmed to be associated with HR-HPV-positive cervical cancer and breast cancer [129, 130]. Overexpression of MALAT1 could reduce miR-124 expression, and subsequently facilitate the growth and metastasis of tongue cancer cells via targeting jagged1 (JAG1), a downstream gene of miR-124. The expression level of JAG1 is positively correlated with MALAT1 but negatively correlated with miR-124 expression, and the elevated JAG1 is essential for MALAT1-mediated cell growth [73].

Overexpression of MALAT1 also induces EMT, promotes migration and invasion, as well as inhibits apoptosis of TSCC cells through the activation of Wnt/ $\beta$-catenin signaling pathway [74]. Besides, Dickkopfrelated protein 1 (DKK1), a repressor of Wnt signaling pathway, has been found effectively eliminated the effects of exogenous MALAT1 on vimentin (upregulated) and E-cadherin (down-regulated), providing a promising therapeutic strategy for TSCC treatment [74]. Recent studies have shed new light on the participation of IncRNAs in tumor initiation and development by modulating protein-coding genes. Knockdown of MALAT-1 leads to the increased expression of several members of small proline-rich proteins (SPRR) in TSCC cells, and high expression levels of certain SPRR proteins (such as SPRR2A) can inhibit the distant metastatic potential of TSCC cells in vivo [75].

\section{MEG3}

Maternally Expressed Gene 3 (MEG3) is an imprinted gene located at chromosome 14q32 and encodes a lncRNA which is pervasively expressed in normal tissues and confirmed as a tumor suppressor. However, loss of MEG3 expression has been observed in multiple malignant cancers, including breast cancer, hepatocellular cancer and TSCC [131-133], and MEG3 silencing in cancer cells is mainly associated with its promoter hypermethylation [134]. Moreover, re-expression of MEG3 can inhibit

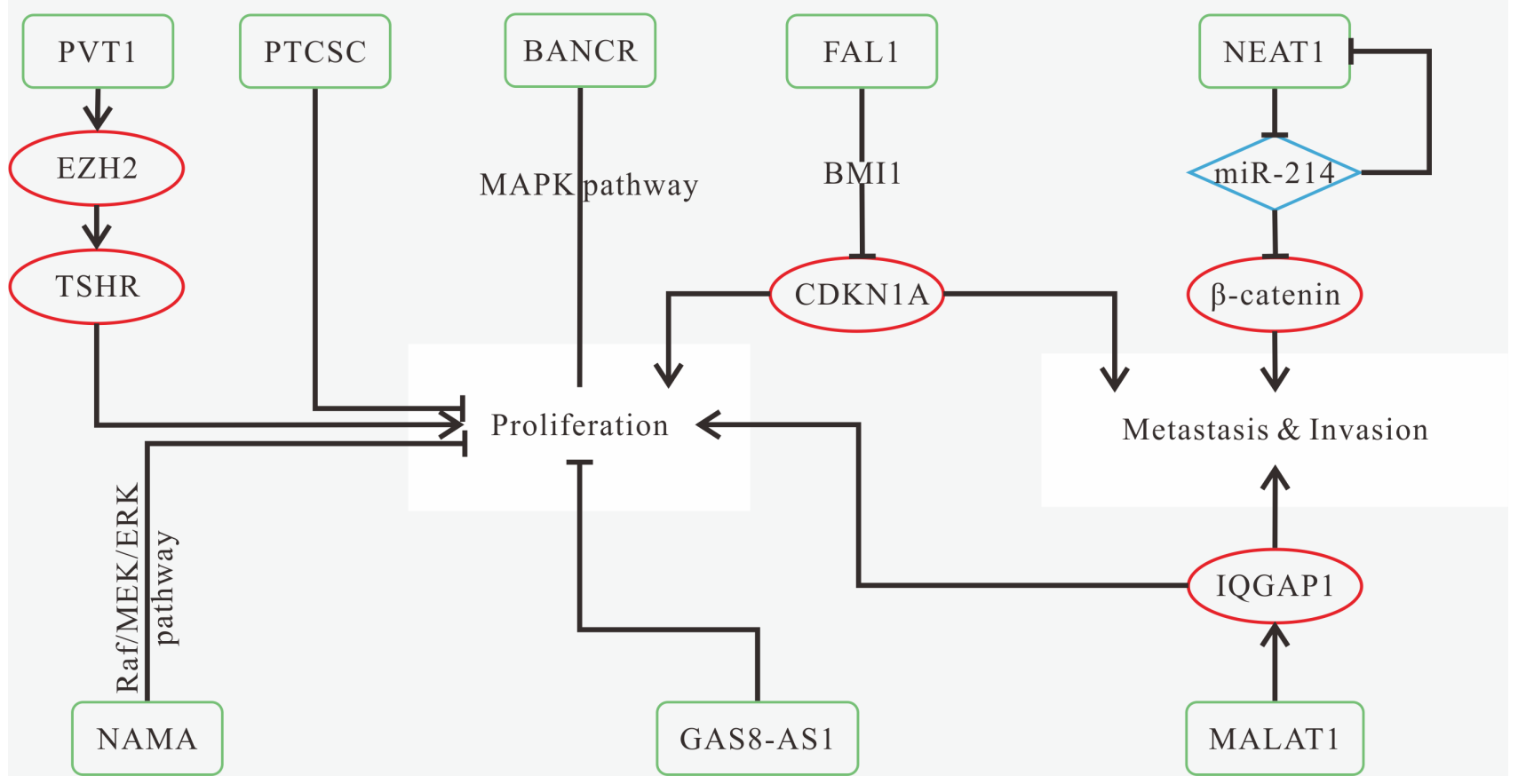

Figure 3: Mechanisms of IncRNAs in TC progression. (A) silencing of PVT1 represses proliferation and decreases cyclin D1 expression through reducing recruitment of EZH2 and modulating TSHR; (B) down-regulated PTCSC3 promotes cell growth and inhibits apoptosis; (C) BANCR overexpression inhibits cell proliferation and invasion, and induces apoptosis through inactivation of ERK and p38 in PTC cell lines (TPC-1, K1, and BCPAP); (D) FAL1 can reduce the expression of CDKN1A via binding to BMI1, thus promoting proliferation and migration; (E) NEAT1 promotes migration and invasion, as well as increases the expression of $\beta$-catenin through the reduction of miR214; (F) downregulation of NAMA inhibits apoptosis via modulating Raf- MEK-ERK signaling pathway; (G) down-regulated GAS8-AS1 promotes cell viability; (H) MALAT1 promotes proliferation and invasion by up-regulating the expression of IQGAP1 in FTC. 
tumor progression by inducing p53 expression, a tumor suppressor. The expression of p53 is very low in normal tissues due to the rapid ubiquitin-proteasome-mediated degradation, while re-expression of MEG3 can stimulate p53 transcription, reduce its degradation and increase its protein levels in tumor cells [134].

Recently, the expression levels of MEG3 and miR26a have been found significantly decreased in TSCC tissues and correlated with TSCC progression [133]. MiR26a has been known to inhibit DNA methyltransferase 3B (DNMT3B) transcripts. Also, experiments have demonstrated that miR-26a can increase the expression of unmethylated MEG3, suggesting that MEG3 can be upregulated by the inhibitory effect of miR-26a on DNMT3B transcripts. Furthermore, MEG3 accumulation inhibits cell proliferation and causes cell cycle arrest and apoptosis of TSCC cell lines (SCC-15 and CAL27) [133]. The same mechanism has also been reported in hepatocellular carcinoma, and miR-26a regulates cell proliferation and migration by modulating DNMT3B/MEG3 axis [135]. Patients with low MEG3 expression have statistically shorter OS than those with high MEG3 expression, suggesting MEG3 can function as a tumor suppressor and independent predictive factor for TSCC patients [133].

\section{NKILA}

Nuclear Factor- $\kappa$ B Interacting LncRNA (NKILA), encoded by the gene located on chromosome 20q13, has been reported to be down-regulated in TSCC tissues and the tissue samples with high tumor node metastasis (TNM) stage. In vitro experiments have demonstrated that NKILA expression is negatively correlated with TSCC metastasis [136].

Aberrant NF- $\kappa \mathrm{B}$ activation affects the occurrence and development of multiple cancers [137]. NF- $\kappa \mathrm{B}$ is released for DNA binding and transcriptional activation by

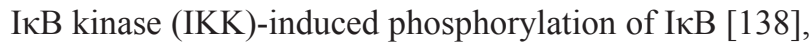
and the increased NF- $\kappa \mathrm{B}$ activity leads to the enhancement of tumor cell invasion ability. In the previous study of breast cancer [139], NKILA transcription was induced by $\mathrm{NF}-\kappa \mathrm{B}$ signaling pathway, while NKILA expression and $\mathrm{NF}-\kappa \mathrm{B}$ activity were negatively correlated. NKILA can inhibit NF- $\kappa \mathrm{B}$ activation by suppressing IKK-induced IKB $\alpha$ phosphorylation but not IKK activity, resulting in the repression of tumor cell migration and invasion. NKILA associates with the NF- $\kappa \mathrm{B}$ : I $\kappa \mathrm{B} \alpha$ complex via

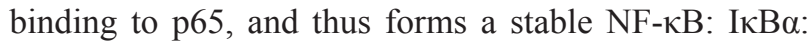
NKILA complex. The formation of NF- $\kappa \mathrm{B}: \mathrm{I} \kappa \mathrm{B} \alpha$ : NKILA complex is the core of the whole process. The molecular mechanism has also been confirmed in TSCC [136], breast cancer [139] and melanoma [140].

$\mathrm{NF}-\kappa \mathrm{B}$ plays a pivotal role in regulating tumor cell EMT. The down-regulated NKILA can significantly decrease E-cadherin expression, while increase the expression of $\mathrm{N}$-cadherin, twist and vimentin. Moreover,
NKILA regulates cells migration by modulating NF- $\kappa \mathrm{B} /$ Twist pathway. These results indicate that the reduction of NKILA in TSCC can eliminate the inhibitory effect on $\mathrm{NF}-\kappa \mathrm{B}$, and thereby promote the EMT process as well as migration and invasion in TSCC [136].

Additionally, low NKILA expression is significantly correlated with advanced clinical stage, tumor size and lymph node metastasis in TSCC [136]. In conclusion, NKILA can affect TSCC progression and metastasis, and function as a prognostic biomarker for TSCC.

\section{UCA1}

Urothelial cancer-associated 1 (UCA1) was first thought to participate in bladder cancer invasion and progression. It is one of the lncRNAs correlated with tumor lymph node metastasis. The expression level of UCA1 in TSCC cells with lymph node metastasis (LNM) is significantly higher than those without LNM. Compared with primary tumors, the increased UCA1 expression in lymph node metastasis indicates that overexpression of UCA1 can enhance cell migration in TSCC. Moreover, it is reported that the elevated UCA1 has little effect on TSCC cell proliferation [141]. Until then, the specific mechanisms about how UCA1 contributes to TSCC remain unclear.

\section{LINC00673}

Compared to adjacent non-tumor tissues, lncRNA LINC00673 is highly expressed in TSCC tissues. High LINC00673 expression was positively correlated with tumor size, invasion muscles of tongue and higher TNM stage [142]. Knockdown of LINC00673 inhibits the migration and invasive properties of TSCC cell lines (Tca8113 and Cal27). Up-regulated LINC00673 is positively correlated with tumor size, higher TNM stage and relapse. Additionally, the expression level of LINC00673 is negatively associated with OS and relapsefree survival [142]. In summary, LINC00673 can be regarded as a regulator of TSCC progression, as well as prognostic predictor of TSCC.

\section{Application}

OSCC is one of the squamous cell carcinomas, and the prognosis of young people is reported to be poor and aggressive [143]. Biomarkers to detect TSCC have been reported, but the conclusions are not so reliable [144].

Either high expression of HOTTIP, LINC00152, LINC00673, MALAT1 and UCA1, or low expression of AC007392.4, MEG3 and NKILA is found in tumor tissues [75, 133, 136, 141, 142, 145, 146]. The known mechanisms of TSCC-related lncRNAs are shown in Figure 4. Knockdown of LINC00673, MALAT1 and UCA1, and overexpression of MEG3 and NKILA can inhibit tumor progression, which might become prospective treatment methods [133, 136, 141]. Patients with high expression of HOTTIP, LINC00152 and 
LINC00673 as well as low expression of MEG3 and NKILA have poorer OS [133, 142, 145, 146]. MALAT1, NKILA and UCA1 are associated with lymph node metastasis $[75,136,141]$.

\section{OSCC-associated IncRNAs}

\section{HOTAIR}

Mechanistically, HOTAIR induces gene silencing through interactions with histone methyltransferase polycomb repressive complex 2 (PRC2) and histone demethylase lysine-specific demethylase 1 (LSD1). HOTAIR recruits the PRC2 and LSD1/ CoREST (REST corepressor 1) / REST (RE1-silencing transcription factor) complexes to target gene, and represses gene transcription via reprograming chromatin states caused by PRC2mediated histone $\mathrm{H} 3$ lysine 27 (H3K27) tri-methylation and LSD1-mediated histone $\mathrm{H} 3$ lysine 4 (H3K4) demethylation [147].

In OSCC, HOTAIR interference induces cell cycle arrest in the G0/G1 phase and apoptosis [148]. As mentioned above, HOTAIR involves in epigenetic modification, and E-cadherin expression can be reduced partly by enrichment of EZH2 [149]. HOTAIR accumulation down-regulates E-cadherin expression via recruiting $\mathrm{EZH} 2$ and $\mathrm{H} 3 \mathrm{~K} 27 \mathrm{me} 3$ to the E-cadherin promoter, and thus increases OSCC cell motility, favoring tumor cell migration and invasion [149]. These results suggest that HOTAIR might be related to the inducement of EMT in OSCC cells.

\section{PTENP1}

PTENP1, a ceRNA, can protect PTEN transcripts from being degraded by PTEN-targeting miRNAs.
PTENP1 can increase PTEN expression in OSCC cell lines via competitively binding to miR-21, leading to the inhibition of proliferation and colony formation [150]. Furthermore, cells at S phase has increasing trends while cells at G2/M phase has decreasing trends due to overexpression of either PTEN or PTENP1. PTENP1 overexpression induces cell cycle arrest at S-G2/M phase via restraining the AKT pathway in OSCC [150]. Previously, it has been verified that loss of PTEN activity resulted in PIP3 accumulation, which could have the same effect as PI3K on activating its downstream effector AKT, and then the activated AKT contributed to malignant tumors [151]. In conclusion, both PTENP1 and PTEN can serve as tumor suppressors and reduces HNSCC tumorigenicity.

\section{UCA1}

Research has found UCA1 affects OSCC through different mechanisms [152]. UCA1 overexpression is positively correlated with the activation of $\mathrm{Wnt} / \beta$-catenin signaling pathway. UCA1 silencing in OSCC cells could repress proliferation, metastasis and invasion, as well as induce apoptosis via modulating the $\mathrm{Wnt} / \beta$-catenin signaling pathway and the expression of downstream genes. Knockdown of UCA1 inhibits tumor growth in vivo, suggesting that UCA1 may provide a lncRNA-oriented diagnostic and therapeutic strategy for OSCC [152]. The similar mechanism was also found in breast cancer [153].

UCA1 has also been reported to be associated with drug resistance in breast and gastric cancer. Knockdown of UCA1 increases the sensitivity to tamoxifen in breast cancer through inhibition of Wnt/ $\beta$-catenin pathway [154], and also promotes chemotherapy sensitivity to adriamycin in gastric cancer and accelerates cellular apoptosis pathway [155]. These findings of drug sensitivity in other

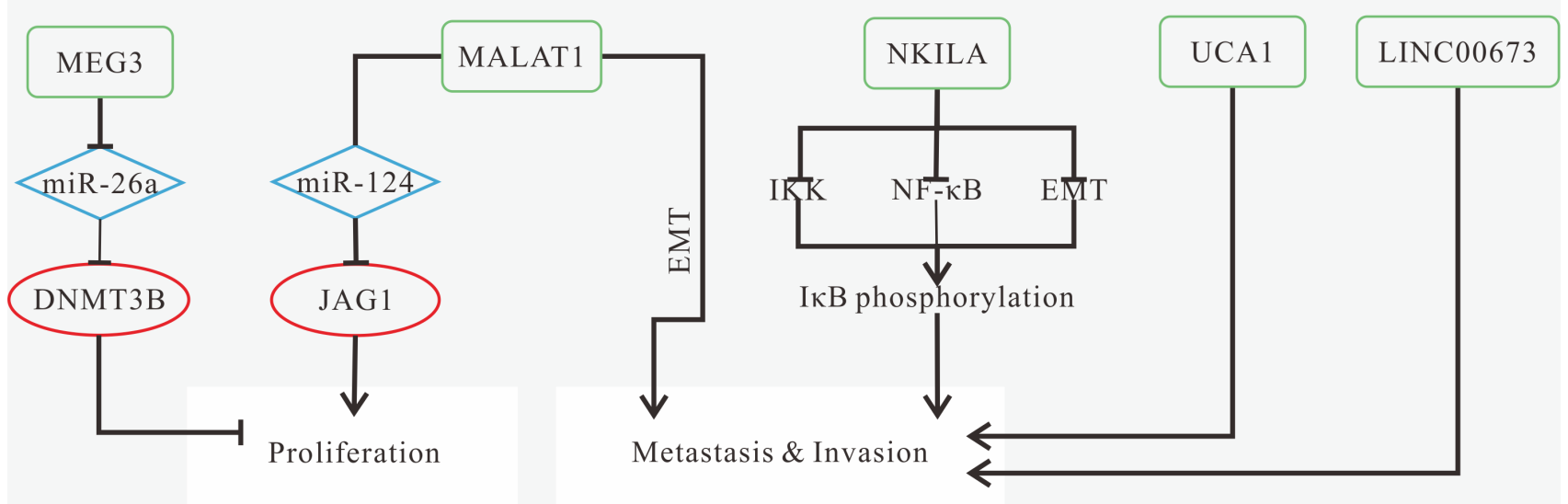

Figure 4: Mechanisms of IncRNAs in TSCC progression. (A) down-regulated MEG3 results in miR-26a overexpression, and then reduce DNMT3B expression, thus promoting cell proliferation and inhibiting apoptosis; (B) MALAT1 overexpression promotes tumor growth and invasion by increasing JAG1 expression resulted from the reduction of miR-124; induces EMT; (C) down-regulated NKILA promotes tumor cell migration and invasion via promoting I $\mathrm{B} \alpha$ phosphorylation induced by IKK, NF- $\mathrm{B}$ activation and the induction of EMT process; (D) UCA1 promotes migration; (E) LINC00673 promotes migration and invasion. 
cancers may provide promising therapeutic strategies for OSCC patients.

\section{FOXCUT}

FOXC1 upstream transcript (FOXCUT), a novel lncRNA associated with tumorigenesis, is transcribed from the upstream region of FOXC1 promoter. Studies have demonstrated that FOXC1 is a cancer-associated gene and its overexpression contributes to poor survival in the patients with breast cancer, OSCC, hepatocellular carcinoma, and so on [156-158]. Recently, the "lncRNAmRNA pair" formed by lncRNA FOXCUT and mRNA FOXC1, has been verified to play a significant role in tumor progression. FOXC1 expression is positively correlated with FOXCUT's in OSCC, and both of them are over-expressed in OSCC patients [157]. Knockdown of either FOXC1 or FOXCUT can remarkably inhibit cell proliferation, migration and invasion, and also reduce the expression levels of matrix metalloproteinases (MMPs) and VEGF-A [157].

\section{FTH1P3}

Ferritin heavy chain 1 pseudogene 3 (FTH1P3), a member of the ferritin heavy chain (FHC) gene family, has been confirmed to be responsible for progression and metastasis of OSCC cells [159]. A recent study has revealed that FTH1P3 is over-expressed in OSCC, and FTH1P3 overexpression contributes to the poorer OS of OSCC patients [160]. Ectopically expressed FTH1P3 can promote proliferative capacity and colony-forming ability in OSCC. Mechanistically, FTH1P3 acts as a ceRNA to sponge miRNA-224-5p, and then the down-regulated miR-224-5p activates frizzled 5 expression at the posttranscription level via alleviating the inhibition of the Wnt/ $\beta$-catenin signaling [160]. The same mechanism was also found in breast cancer [161]. To conclude, both FTH1P3 and frizzled 5 are up-regulated in OSCC cells, and overexpression of frizzled 5 also has an oncogenic effect on OSCC progression [160, 161].

\section{TUG1}

The lncRNA, taurine up-regulated gene 1 (TUG1), has been found up-regulated in OSCC tissues and cell lines. The expression level of TUG1 in OSCC tissues is higher than that in normal adjacent tissues. TUG1 knockdown inhibits cell growth, proliferation, colonyforming ability and invasion, as well as induces cell apoptosis via inhibiting the $\mathrm{Wnt} / \beta$-catenin signaling pathway in OSCC. These effects could be reversed by the LiCl-mediated activation of $\mathrm{Wnt} / \beta$-catenin signaling pathway [162]. The findings indicate that TUG1 may serve as a novel target for OSCC treatment, and further study should be performed to evaluate it.

\section{Application}

Although clinical treatment has made some progress, the OS rate of OSCC is still just about 50-60\% $[163,164]$. This is mainly due to the difficulty of early detection. During the initial diagnosis, over $50 \%$ of cases of show lymph node metastasis $[165,166]$. LncRNAs may act as early predictors in OSCC and be combined with surgery therapy.

Either up-regulation of CCAT2, FOXCUT, FTH1P3, HOTAIR, TUG1 and UCA1, or down-regulation of PTENP1 could be biomarkers for OSCC diagnosis [148, $150,152,157,160,162,167]$. The known mechanisms of OSCC-related lncRNAs are shown in Figure 5. HOTAIR expression level is associated with clinical stage [148, 167]. Although several lncRNAs alter their expression levels in cancer cells, only HOTAIR and MALALT-1 detected in the saliva has statistically difference and may act as a rapid and noninvasive diagnostic strategies [168]. Changes of the expression of downstream molecule miR-375 was also found in saliva [169]. MiR-375 is regulated by HNGA1 in HNSCC [167], and whether the same regulation exists in OSCC remains unclear.

Knockdown of CCAT2, FOXCUT, HOTAIR, TUG1 and UCA1 can suppress various aspects of tumor progression [148, 152, 157, 162]. Therapies targeted at FTH1P3-miR-224-5p-frizzled 5 axis or PTENP1-miR-21 axis might also be new treatment methods [160]. Patients with high expression of CCAT2, FOXCUT, FTH1P3 and HOTAIR or low expression of PTENP1 have poorer OS $[148,150,157,160]$. CCAT2 is associated with tumor grade and distant metastasis. HOTAIR is related to tumor size $[148,167]$.

\section{LSCC-associated IncRNAs}

\section{NEAT1}

Emerging evidence has presented that NEAT1 is over-expressed in HNC and participates in tumorigenesis and tumor progression through interactions with miRNAs. NEAT1 knockdown represses cell proliferation and invasion, induce G1 phase arrest and apoptosis in LSCC, as well as inhibit LSCC xenograft growth [170]. NEAT1 promotes LSCC progression because it could stimulate the expression of miR-107-targeting cyclin-dependent kinase 6 (CDK6) through the inhibition of miR-107 in LSCC [170]. On the contrary, overexpression of miR-107 significantly reduces CDK6 expression [170], which might be a potential therapeutic strategy for LSCC patients. The same molecular mechanism has been found in glioma stem cells [171]. Knockdown of NEAT1 can suppress glioma stem-like properties via modulating the miR-107/CDK6 pathway, but whether NEAT1 knockdown has the same effect on LSCC needs further investigation. 


\section{PVT1\&LOC157273}

Specific mRNAs are responsible for over-represented cell cycle and proteasome pathways in lymph node metastatic LSCC. PVT1 could decrease the expression of hsa-miR-1207-5p, and increase the expression of Glucose-6-phosphate dehydrogenase (G6PD) in LSCC cells, a downstream target of miR-1207-5p involved in the proteasome pathway [172]. A novel lncRNA LOC157273 expression has been reported increased in lymph node metastatic LSCC cell lines. It has been found to be correlated with the aberrant expression of hsa-miR-145-5p (downregulated), as well as miR-145-5p's downstream molecules CDK4 and SMC1A (up-regulated) [172]. The networks integrated by lncRNA PVT1, miR-1207-5p and mRNA G6PD, or composed of lncRNA LOC157273, miR-145-5p, as well as mRNAs CDK4 and SMC1A, play an important role in cell-cycle regulation, and might function as promising biomarkers for lymph node metastatic LSCC diagnosis.

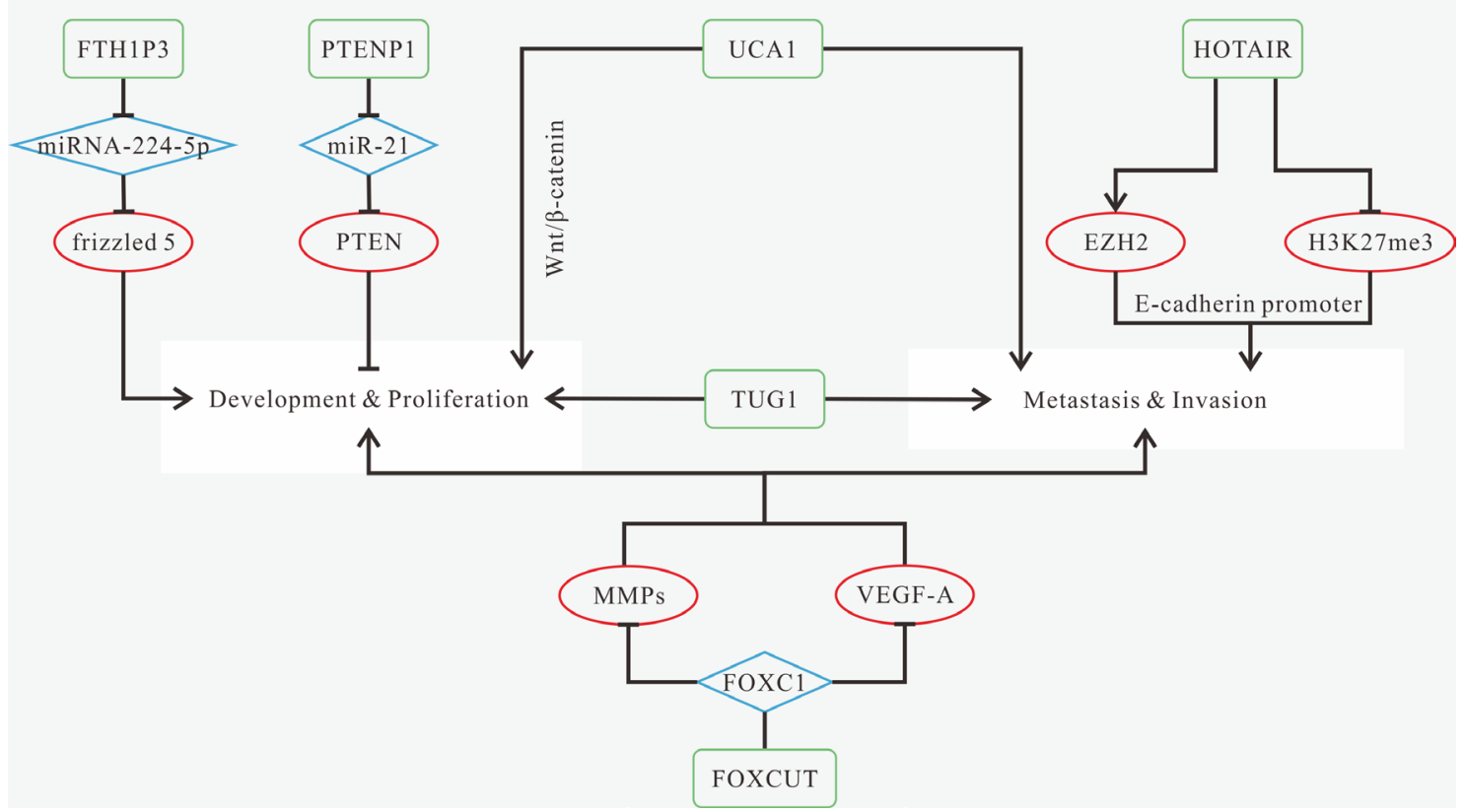

Figure 5: Mechanisms of IncRNAs in OSCC progression. (A) FTH1P3 promotes proliferation and colony formation via acting as a miRNA sponge of miRNA-224-5p to activate frizzled 5 expression; (B) PTENP1 can inhibit proliferation and colony formation through acting as a ceRNA of miR-21 to increase PTEN expression; (C) up-regulated UCA1 promotes proliferation, metastasis and invasion, as well as inhibits cell apoptosis via modulating the Wnt/ $\beta$-catenin signaling pathway; (D) HOTAIR promotes cell proliferation, migration and invasion, and inhibits apoptosis by recruiting EZH2; (E) TUG1 promotes cell growth, proliferation, colony-forming ability and invasion; (F) FOXCUT promotes cell proliferation, migration and invasion via increasing the expression levels of MMPs and VEGF-A, which is regulated by "FOXC1- FOXCUT pair".

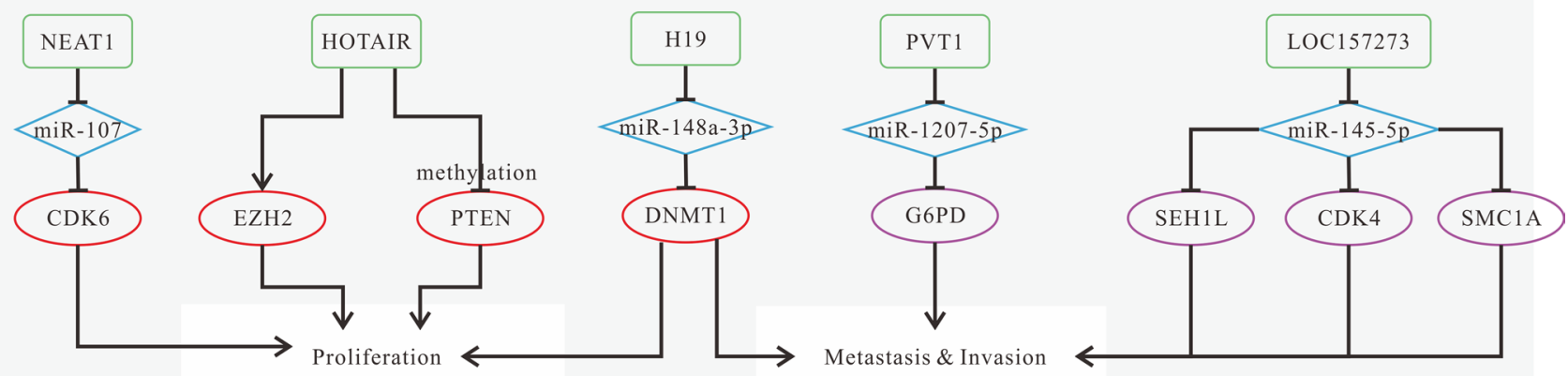

Figure 6: Mechanisms of IncRNAs in LSCC progression. (A) NEAT1 promotes proliferation and invasion, and inhibits apoptosis via regulating miR-107/CDK6 axis; (B) HOTAIR promotes invasion and inhibits apoptosis by inducing PTEN methylation; (C) H19 promotes proliferation, migration and invasion by the lncRNA H19/miR-148a-3p/DNMT1 axis; (D) The network composed of lncRNA PVT1, miR-12075p, and mRNA G6PD might function as promising biomarkers for lymph node metastatic LSCC diagnosis; (E) LOC157273 plays an important role in cell-cycle regulation via the network integrated with miR-145-5p, and mRNAs CDK4 and SMC1A in lymph node metastatic LSCC. 


\section{HOTAIR}

Phosphorylation of PRC2 complex member EZH2 at the post-translational level results in a stronger binding affinity between HOTAIR and EZH2 [173]. The expression level of HOTAIR is up-regulated in LSCC tissues [174, 175]. HOTAIR silencing impairs invasive ability, and induces apoptosis of LSCC cell line Hep-2 [174], but enhances proliferative capacity and attenuates the resistance to cis-platinum in AMC-HN8 cells [175]. HOTAIR-induced hypermethylation of $\mathrm{CpG}$ islands in PTEN promoter, a tumor suppressor, leads to a sharp decrease of PTEN expression in Hep-2 cells, indicating that HOTAIR might play an oncogenic role in LSCC progression through activation of the phosphatidylinositol 3-kinase (PI3K) signaling pathway induced by PTEN methylation $[174,176]$.

\section{H19}

Overexpression of H19 is associated with tumor grade, differentiation, neck lymph node metastasis, clinical stage, and OS [177]. As a miRNA sponge, lncRNA H19 involves in LSCC progression via modulating miR-148a-3p and DNA methyltransferase enzyme DNMT1 [177]. H19-induced decrease of miR-148a-3p eliminates the inhibitory effect of miR-148a-3p on DNMT1, thus promoting proliferation, metastasis and invasion via increasing DNA methylation in LSCC [177]. The activity of miR-148a-3p is required during the process above. However, miR148a-3p overexpression had little effect on the expression level of H19 [177].

\section{Application}

LSCC ranks the second among malignant lesion of upper aerodigestive tract. Treatment varies from surgery to a combination of surgery and radiotherapy [178]. However, the optimal treatment of LSCC remains unclear [179].

Knockdown of LINC00673, MALAT1 and UCA1 or overexpression of NKILA can inhibit cell migration $[75,136,141,142]$. Overexpressed MEG3 can arrest cell cycle, inhibit tumor cell proliferation, and promote apoptosis [133]. AC007392.4 influences tumor cell growth and cell apoptosis rate [180]. As NKILA is associated with NF- $\kappa B, N F-\kappa B$ inhibitor (Bay-117082 or JSH-23) can inhibit tumor cell metastasis [136].

AC007392.4, MEG3, NKILA are down-regulated in LSCC, while up-expression of HOTTIP, LINC00152, LINC00673, MALAT1, UCA1 is observed [75, 133, 136, 141, 142, 145, 146, 180]. Moreover, Highly expressed LINC00673 is associated with higher TNM stage [142]. MALAT1 and UCA1 are highly expressed in patients with LNM stage [75, 141]. For prognosis, patients with highexpression of HOTTIP, LINC00152 and LINC00673, or low expression of MEG3 and/or NKILA have poorer OS $[133,136,142,145,146]$. Highly expressed LINC00673 is associated with tumor size and relapse [142]. Downregulated NKILA or highly expressed MALAT1 and UCA1 are associated with tumor metastasis, especially lymph node metastasis $[75,136,141]$. The known mechanisms of LSCC-related lncRNAs are shown in Figure 6.

\section{CONCLUSIONS}

LncRNAs can modulate HNC tumorigenesis and development at diverse levels. They can participate in $\mathrm{HNC}$ progression via modulating gene expression at epigenetic, transcriptional, post-transcriptional and translational levels. For instance, lncRNA modulates tumor progression by altering the expression of proteins associated with cell proliferation, metastasis, and cell cycle. The regulatory role of lncRNA in various signaling pathways cannot be ignored. Additionally, lncRNAs can regulate miRNA-mediated downstream effector molecules by acting as a ceRNA for miRNAs, and the interactions between lncRNAs and miRNAs suggest a potential target for HNC treatment. Recently, the network composed of lncRNAs, mRNAs and miRNAs might provide an innovative idea for future research. Also, many of the mechanisms that have matured in other tumors have not yet been validated in $\mathrm{HNC}$, and have led to new directions for future research. Radiotherapy and chemotherapy are still the most important treatment measures, but the effects of these methods still need to be improved, and patients' discomfort caused by them is difficult to remove. Experiments have shown that some lncRNAs can improve the sensitivity of tumor cells to radiotherapy and chemotherapy.

In this review, we enumerate the functions and molecular mechanisms of dysregulated lncRNAs that have been confirmed to be involved in HNC until now. They may function as oncogenes or tumor inhibitors in HNC progression. Statistics and experiments have proved that some lncRNAs can serve as diagnostic, prognostic biomarkers, as well as provide promising therapeutic strategies for HNC patients. Since many lncRNAs have remained to be investigated, further research is required to determine precise, detailed functions and mechanisms of these lncRNAs in clinical practice.

\section{Abbreviations}

HNC: head and neck cancer; HNSCC: head and neck squamous cell carcinoma; HPV: human papillomavirus; NcRNAs: non-coding RNAs; LncRNAs: long non-coding RNAs; OSCC: oral squamous cell carcinoma; LSCC: laryngeal squamous cell carcinoma; TSCC: tongue squamous cell carcinoma; HSCC: Hypopharyngeal squamous cell carcinoma; NPC: nasopharyngeal carcinoma; TC: Thyroid cancer; PTC: papillary thyroid cancer; FTC: follicular thyroid cancer; ATC: anaplastic thyroid cancer; MTC: medullary thyroid cancer; DTC: differentiated thyroid cancer; PDTC: poorly differentiated thyroid cancer; HOTAIR: HOX transcript antisense RNA; RBPs: RNA binding proteins; 
ceRNA: competing endogenous RNA; IGF2: Insulin-like growth factor 2; LOI: loss of imprinting; JNA: juvenile nasopharyngeal angiofibroma; OS: overall survival; HNGA1: HNSCC glycolysis-associated 1; DFS: diseasefree survival; VEGFA: vascular endothelial growth factor-A; GRP78: glucose-regulated protein 78; EMT: Epithelial-Mesenchymal Transition; EZH2: enhancer of zeste homolog 2; MALAT1: Metastasis-associated lung adenocarcinoma transcript 1; CSC: cancer stem cell; ANRIL: antisense non-coding RNA in the INK4 locus; CBX7: Chromobox 7; SP cells: side population cells; AFAP1-AS1: Actin filament associated protein 1 antisense RNA1; PARP: poly (ADP-ribose) polymerase; BANCR: BRAF-activated non-coding RNA; TSHR: thyroid-stimulating hormone receptor; PTCSC: papillary thyroid cancer susceptibility candidate; SNP: single nucleotide polymorphism; MYH9: Myosin-9; NEAT1: Nuclear Enriched Abundant Transcript 1; FAL1: Focally amplified lncRNA on chromosome 1; CDKN1A/p21: cyclin-dependent kinase inhibitor 1A; BMI1: BMI1 proto-oncogene; CDK: cyclin-dependent kinase; RB: retinoblastoma protein; GAS8-AS1: growth arrestspecific 8-antisense RNA 1; NAMA: noncoding RNA associated with mitogen-activated protein kinase pathway and growth arrest; IQGAP1: IQ motif containing GTPase activating protein 1; JAG1: jagged1; DKK1: Dickkopfrelated protein 1; SPRR: small proline-rich proteins; MEG3: Maternally Expressed Gene 3; DNMT3B: DNA methyltransferase 3B; NKILA: Nuclear Factor$\kappa \mathrm{B}$ Interacting LncRNA; TNM: tumor node metastasis; IKK: IкB kinase; UCA1: Urothelial cancer-associated 1; LNM: lymph node metastasis; PRC2: polycomb repressive complex 2; LSD1: lysine-specific demethylase 1; CoREST: REST corepressor 1; REST: RE1-silencing transcription factor; H3K27: histone H3 lysine 27; H3K4:histone H3 lysine 4; FOXCUT: FOXC1 upstream transcript; MMPs: matrix metalloproteinases; FTH1P3: Ferritin heavy chain 1 pseudogene 3; FHC: ferritin heavy chain; TUG1: taurine up-regulated gene 1; CDK6: cyclin-dependent kinase 6; G6PD: Glucose-6-phosphate dehydrogenase; PI3K: phosphatidylinositol 3-kinase;

\section{ACKNOWLEDGMENTS}

We thank Prof. Hao Zhang for helpful discussion.

\section{CONFLICTS OF INTEREST}

No potential conflicts of interest exist.

\section{FUNDING}

This study was supported by Science and Technology Plan of Sichuan Province (2017KZ0022) and Scientific Research Foundation for Young Investigators of Sichuan University (2017SCU11009). The funder had no role in study design, data collection and analysis, decision to publish, or preparation of the manuscript.

\section{REFERENCES}

1. Petersson F. Nasopharyngeal carcinoma: A review. Semin Diagn Pathol. 2015; 32:54-73. https://doi.org/10.1053/j. semdp.2015.02.021.

2. Metcalfe CW, Lowe D, Rogers SN. What patients consider important: temporal variations by early and late stage oral, oropharyngeal and laryngeal subsites. J Craniomaxillofac Surg. 2014; 42:641-7. https://doi.org/10.1016/j.jcms.2013.09.008.

3. Rettig EM, D'Souza G. Epidemiology of Head and Neck Cancer. Surgical Oncology Clinics of North America. 2015; 24:379-96. http://doi.org/10.1016/j.soc.2015.03.001.

4. Argiris A, Karamouzis MV, Raben D, Ferris RL. Head and neck cancer. Lancet. 2008; 371:1695-709.

5. Belcher R, Hayes K, Fedewa S, Chen AY. Current treatment of head and neck squamous cell cancer. Journal of Surgical Oncology. 2014; 110:551-74. https://doi.org/10.1002/jso.23724.

6. Boffetta P, Hashibe M, INHANCE Consortium OBO. Alcohol drinking in never-tobacco users and cigarette smoking in never drinkers: pooled analysis in the International Head and Neck Cancer Epidemiology (INHANCE) consortium. Cancer Research. 2007; 67:863.

7. Leemans CR, Braakhuis BJ, Brakenhoff RH. Response to correspondence on the molecular biology of head and neck cancer. Nat Rev Cancer. 2011; 11:382.

8. Mao L, Hong WK, Papadimitrakopoulou VA. Focus on head and neck cancer. Cancer Cell. 2004; 5:311-6. http:// doi.org/10.1016/S1535-6108(04)00090-X.

9. Spence T, Bruce J, Yip K, Liu FF. HPV Associated Head and Neck Cancer. Cancers. 2016; 8:75.

10. Warnakulasuriya S. Global epidemiology of oral and oropharyngeal cancer. Oral Oncol 45: 309-316. Oral Oncology. 2008; 45:309-16.

11. Siegel R, Ward E, Brawley O, Jemal A. Cancer statistics, 2011: the impact of eliminating socioeconomic and racial disparities on premature cancer deaths. CA Cancer J Clin. 2011; 61:212.

12. Almadori G, Bussu F, Cadoni G, Galli J, Paludetti G, Maurizi M. Molecular markers in laryngeal squamous cell carcinoma: Towards an integrated clinicobiological approach. European Journal of Cancer. 2005; 41:683-93.

13. Jemal A, Siegel R, Ward E, Murray T, Xu J, Thun MJ. Cancer statistics, 2007. CA Cancer J Clin. 2007; 57:43-66.

14. Patel RS, Clark JR, Dirven R, Wyten R, Gao K, O'Brien CJ. Prognostic factors in the surgical treatment of patients with oral carcinoma. ANZ journal of surgery. 2009; 79:19-22.

15. Franceschi D, Gupta R, Spiro RH, Shah JP. Improved survival in the treatment of squamous carcinoma of the oral tongue. The American Journal of Surgery. 1993; 166:360-5.

16. Hall SF, Groome PA, Irish J, O'Sullivan B. The natural history of patients with squamous cell carcinoma of the hypopharynx. Laryngoscope. 2008; 118:1362. 
17. Lehnerdt GF, Franz P, Zaqoul A, Schmitz KJ, Grehl S, Lang S, Schmid KW, Siffert W, Jahnke K, Frey UH. Overall and relapse-free survival in oropharyngeal and hypopharyngeal squamous cell carcinoma are associated with genotypes of T393C polymorphism of the GNAS1 gene. Clinical Cancer Research. 2008; 14:1753-8.

18. Lim YC, Park HY, Hwang HS, Kang SU, Pyun JH, Lee $\mathrm{MH}$, Choi EC, Kim CH. (-)-Epigallocatechin-3-gallate (EGCG) inhibits HGF-induced invasion and metastasis in hypopharyngeal carcinoma cells. Cancer letters. 2008; 271:140-52.

19. Davies L, Welch HG. Epidemiology of head and neck cancer in the United States. Otolaryngology-Head and Neck Surgery. 2006; 135:451-7. e3.

20. Lothaire P, de Azambuja E, Dequanter D, Lalami Y, Sotiriou C, Andry G, Castro G, Awada A. Molecular markers of head and neck squamous cell carcinoma: promising signs in need of prospective evaluation. Head \& neck. 2006; 28:256-69.

21. Tang LL, Chen WQ, Xue WQ, He YQ, Zheng RS, Zeng YX, Jia WH. Global trends in incidence and mortality of nasopharyngeal carcinoma. Cancer letters. 2016; 374:22-30.

22. Jemal A, Bray F, Center MM, Ferlay J, Ward E, Forman D. Global cancer statistics. CA Cancer J Clin. 2011; 61:69-90.

23. Marks JE, Phillips JL, Menck HR. The National Cancer Data Base report on the relationship of race and national origin to the histology of nasopharyngeal carcinoma. Cancer. 1998; 83:582-8.

24. Wu A, Wu K, Li J, Mo Y, Lin Y, Wang Y, Shen X, Li S, Li L, Yang Z. Let-7a inhibits migration, invasion and epithelial-mesenchymal transition by targeting HMGA2 in nasopharyngeal carcinoma. Journal of translational medicine. 2015; 13:105.

25. Wei WI, Sham JS. Nasopharyngeal carcinoma. The Lancet. 2005; 365:2041-54.

26. Xing M. Molecular pathogenesis and mechanisms of thyroid cancer. Nature Reviews Cancer. 2013; 13:184-99.

27. Board PATE. Thyroid Cancer Treatment (PDQ $\left.{ }^{\circledR}\right) .2016$.

28. Zecha JA, Raber-Durlacher JE, Nair RG, Epstein JB, Sonis ST, Elad S, Hamblin MR, Barasch A, Migliorati CA, Milstein DM, Genot MT, Lansaat L, van der Brink R, et al. Low level laser therapy/photobiomodulation in the management of side effects of chemoradiation therapy in head and neck cancer: part 1: mechanisms of action, dosimetric, and safety considerations. Supportive Care in Cancer. 2016; 24:278192. https://doi.org/10.1007/s00520-016-3152-z.

29. Zecha JA, Raber-Durlacher JE, Nair RG, Epstein JB, Elad S, Hamblin MR, Barasch A, Migliorati CA, Milstein DM, Genot MT, Lansaat L, van der Brink R, Arnabat-Dominguez $\mathrm{J}$, et al. Low-level laser therapy/photobiomodulation in the management of side effects of chemoradiation therapy in head and neck cancer: part 2: proposed applications and treatment protocols. Supportive Care in Cancer. 2016; 24:2793-805. https://doi.org/10.1007/s00520-016-3153-y.

30. Dunne S, Mooney O, Coffey L, Sharp L, Desmond D, Timon C, O'Sullivan E, Gallagher P. Psychological variables associated with quality of life following primary treatment for head and neck cancer: a systematic review of the literature from 2004 to 2015. Psycho-Oncology. 2017; 26:149-60. https://doi.org/10.1002/pon.4109.

31. Elham R, Selena ZK, Weg MO. Evaluation of Non-Coding RNAs as Potential Targets in Head and Neck Squamous Cell Carcinoma Cancer Stem Cells. Current Drug Targets. 2014; 15:1247-60. https://doi.org/10.2174/1389450115666 141024113446 .

32. Schmitz SU, Grote P, Herrmann BG. Mechanisms of long noncoding RNA function in development and disease. Cellular and Molecular Life Sciences. 2016; 73:2491-509. https://doi.org/10.1007/s00018-016-2174-5.

33. Mercer TR, Dinger ME, Sunkin SM, Mehler MF, Mattick JS. Specific expression of long noncoding RNAs in the mouse brain. Proceedings of the National Academy of Sciences. 2008; 105:716-21. https://doi.org/10.1073/ pnas.0706729105.

34. Zou AE, Ku J, Honda TK, Yu V, Kuo SZ, Zheng H, Xuan Y, Saad MA, Hinton A, Brumund KT, Lin JH, WangRodriguez J, Ongkeko WM. Transcriptome sequencing uncovers novel long noncoding and small nucleolar RNAs dysregulated in head and neck squamous cell carcinoma. RNA. 2015; 21:1122-34. https://doi.org/10.1261/ rna.049262.114.

35. Yang QQ, Deng YF. Long non-coding RNAs as novel biomarkers and therapeutic targets in head and neck cancers. Int J Clin Exp Pathol. 2014; 1286-92.

36. Gutschner T, Diederichs S. The hallmarks of cancer. RNA Biology. 2012; 9:703-19. https://doi.org/10.4161/rna.20481.

37. Zou AE, Zheng H, Saad MA, Rahimy M, Ku J, Kuo SZ, Honda TK, Wang-Rodriguez J, Xuan Y, Korrapati A, Yu V, Singh P, Grandis JR, et al. The non-coding landscape of head and neck squamous cell carcinoma. Oncotarget. 2016; 7:51211-22. https://doi.org/10.18632/oncotarget.9979.

38. Fayda M, Isin M, Tambas M, Guveli M, Meral R, Altun M, Sahin D, Ozkan G, Sanli Y, Isin H, Ozgur E, Gezer U. Do circulating long non-coding RNAs (lncRNAs) (LincRNA-p21, GAS 5, HOTAIR) predict the treatment response in patients with head and neck cancer treated with chemoradiotherapy? Tumor Biology. 2016; 37:3969-78. https://doi.org/10.1007/s13277-015-4189-1.

39. Chen FJ, Sun M, Li SQ, Wu QQ, Ji L, Liu ZL, Zhou GZ, Cao G, Jin L, Xie HW, Wang CM, Lv J, De W, et al. Upregulation of the long non-coding rna hotair promotes esophageal squamous cell carcinoma metastasis and poor prognosis. Molecular Carcinogenesis. 2013; 52:908-15. https://doi.org/10.1002/mc.21944.

40. Kogo R, Shimamura T, Mimori K, Kawahara K, Imoto S, Sudo T, Tanaka F, Shibata K, Suzuki A, Komune S, Miyano $\mathrm{S}$, Mori M. Long noncoding RNA HOTAIR regulates polycomb-dependent chromatin modification and is associated with poor prognosis in colorectal cancers. Cancer Research. 2011; 71:6320. 
41. Kim K, Jutooru I, Chadalapaka G, Johnson G, Frank J, Burghardt R, Kim S, Safe S. HOTAIR is a negative prognostic factor and exhibits pro-oncogenic activity in pancreatic cancer. Oncogene. 2013; 32:1616-25. https://doi.org/http://www. nature.com/onc/journal/v32/n13/suppinfo/onc2012193s1.html.

42. Kong L, Zhou X, Wu Y, Wang Y, Chen L, Li P, Liu S, Sun S, Ren Y, Mei M, Wang X, Zhang L. Targeting HOTAIR induces mitochondria related apoptosis and inhibits tumor growth in head and neck squamous cell carcinoma in vitro and in vivo. Curr Mol Med. 2015; 15:952-60. https://doi.or g/10.2174/1566524016666151123112716.

43. Xu CZ, Jiang C, Wu Q, Liu L, Yan X, Shi R. A FeedForward Regulatory Loop between HuR and the Long Noncoding RNA HOTAIR Promotes Head and Neck Squamous Cell Carcinoma Progression and Metastasis. Cell Physiol Biochem. 2016; 40:1039-51.

44. Jakstaite A, Maziukiene A, Silkuniene G, Kmieliute K, Gulbinas A, Dambrauskas Z. HuR mediated posttranscriptional regulation as a new potential adjuvant therapeutic target in chemotherapy for pancreatic cancer. World Journal of Gastroenterology. 2015; 21:13004-19. https://doi.org/10.3748/wjg.v21.i46.13004.

45. Pachnis V, Brannan CI, Tilghman SM. The structure and expression of a novel gene activated in early mouse embryogenesis. The EMBO Journal. 1988; 7:673-81.

46. Matouk IJ, DeGroot N, Mezan S, Ayesh S, Abu-lail R, Hochberg A, Galun E. The H19 Non-Coding RNA Is Essential for Human Tumor Growth. Plos One. 2007; 2:e845. https://doi.org/10.1371/journal.pone.0000845.

47. Barsyte-Lovejoy D, Lau SK, Boutros PC, Khosravi F, Jurisica I, Andrulis IL, Tsao MS, Penn LZ. The c-Myc oncogene directly induces the H19 noncoding RNA by allele-specific binding to potentiate tumorigenesis. Cancer research. 2006; 66:5330-7. https://doi.org/10.1158/0008-5472.can-06-0037.

48. Zhang E, Li W, Yin D, De W, Zhu L, Sun S, Han L. c-Mycregulated long non-coding RNA H19 indicates a poor prognosis and affects cell proliferation in non-small-cell lung cancer. Tumour Biol. 2016; 37:4007-15. https://doi. org/10.1007/s13277-015-4185-5.

49. El-Naggar AK, Lai S, Tucker SA, Clayman GL, Goepfert H, Hong WK, Huff V. Frequent loss of imprinting at the IGF2 and $\mathrm{H} 19$ genes in head and neck squamous carcinoma. Oncogene. 1999; 18:7063.

50. Coutinho-Camillo CM, Brentani MM, Butugan O, Torloni $\mathrm{H}$, Nagai MA. Relaxation of imprinting of IGFII gene in juvenile nasopharyngeal angiofibromas. Diagn Mol Pathol. 2003; 12:57-62. https://doi.org/10.1097/00019606200303000-00008.

51. Guan GF, Zhang DJ, Wen LJ, Xin D, Liu Y, Yu DJ, Su K, Zhu L, Guo YY, Wang K. Overexpression of lncRNA H19/miR-675 promotes tumorigenesis in head and neck squamous cell carcinoma. Int J Med Sci. 2016; 13:914-22.

52. Wang Y. Upregulated IncRNA-HNGA1, a target of miR375 , contributes to aerobic glycolysis of head and neck squamous cell carcinoma through increasing levels of the glucose transporter protein SCL2A1. European Journal of Cancer. 2016; 61:S14-S5.

53. Wang Y, Cheng B. Abstract A42: LncRNA-p23154-miR-375 axis regulates OSCC glycolysis by targeting SCL2A1. AACR. 2016.

54. Dahia PL, Fitzgerald MG, Zhang X, Marsh DJ, Zheng Z, Pietsch T, Von DA, Haluska FG, Haber DA, Eng C. A highly conserved processed PTEN pseudogene is located on chromosome band 9p21. Oncogene. 1998; 16:2403-6.

55. Liu J, Yue X, Xu L, Chen W, Wei C, Zhang C. Decreased expression of pseudogenePTENP1promotes malignant behaviours and is associated with the poor survival of patients with HNSCC. Scientific Reports. 2017; 7:41179.

56. Gore-Panter SR, Hsu J, Barnard J, Moravec CS, Van Wagoner DR, Chung MK, Smith JD. PANCR, the PITX2 Adjacent Noncoding RNA, Is Expressed in Human Left Atria and Regulates PITX2c Expression. Circulation Arrhythmia and electrophysiology. 2016; 9:e003197. https://doi.org/10.1161/CIRCEP.115.003197.

57. Quentien MH, Barlier A, Franc JL, Pellegrini I, Brue T, Enjalbert A. Pituitary transcription factors: from congenital deficiencies to gene therapy. J Neuroendocrinol. 2006; 18:633-42. https://doi.org/10.1111/j.1365-2826.2006.01461.x.

58. Weiss G, Cottrell S, Distler J, Schatz P, Kristiansen G, Ittmann M, Haefliger C, Lesche R, Hartmann A, Corman J, Wheeler T. DNA methylation of the PITX2 gene promoter region is a strong independent prognostic marker of biochemical recurrence in patients with prostate cancer after radical prostatectomy. J Urol. 2009; 181:1678-85. https:// doi.org/10.1016/j.juro.2008.11.120.

59. Banez LL, Sun L, van Leenders GJ, Wheeler TM, Bangma $\mathrm{CH}$, Freedland SJ, Ittmann MM, Lark AL, Madden JF, Hartman A, Weiss G, Castanos-Velez E. Multicenter clinical validation of PITX2 methylation as a prostate specific antigen recurrence predictor in patients with post-radical prostatectomy prostate cancer. J Urol. 2010; 184:149-56. https://doi.org/10.1016/j.juro.2010.03.012.

60. Fung FK, Chan DW, Liu VW, Leung TH, Cheung AN, Ngan HY. Increased expression of PITX2 transcription factor contributes to ovarian cancer progression. PLoS One. 2012; 7:e37076. https://doi.org/10.1371/journal.pone.0037076.

61. Sailer V, Holmes EE, Gevensleben H, Goltz D, Droge F, de Vos L, Franzen A, Schrock F, Bootz F, Kristiansen G, Schrock A, Dietrich D. PITX2 and PANCR DNA methylation predicts overall survival in patients with head and neck squamous cell carcinoma. Oncotarget. 2016; 7:75827-38. https://doi.org/10.18632/ oncotarget. 12417.

62. Méry B, Rancoule C, Guy JB, Espenel S, Wozny AS, Battiston-Montagne P, Ardail D, Beuve M, Alphonse G, Rodriguez-Lafrasse C, Magné N. Preclinical models in HNSCC: A comprehensive review. Oral Oncol. 2017; 65:516. https://doi.org/10.1016/j.oraloncology.2016.12.010. 
63. Esteves LI, Javaroni AC, Nishimoto IN, Magrin J, Squire JA, Kowalski LP, Rainho CA, Rogatto SR. DNA methylation in the CTCF-binding site I and the expression pattern of the H19 gene: does positive expression predict poor prognosis in early stage head and neck carcinomas? Molecular Carcinogenesis. 2005; 44:102-10.

64. Nie Y, Liu X, Qu S, Song E, Zou H, Gong C. Long non-coding RNA HOTAIR is an independent prognostic marker for nasopharyngeal carcinoma progression and survival. Cancer Science. 2013; 104:458-64. https://doi.org/10.1111/cas.12092.

65. Fu WM, Lu YF, Hu BG, Liang WC, Zhu X, Yang HD, Li G, Zhang JF. Long noncoding RNA Hotair mediated angiogenesis in nasopharyngeal carcinoma by direct and indirect signaling pathways. Oncotarget. 2016; 7:4712-23. https://doi.org/10.18632/oncotarget.6731.

66. Ng A, Tang JP, Goh CH, Hui KM. Regulation of the H19 imprinting gene expression in human nasopharyngeal carcinoma by methylation. Int J Cancer. 2003; 104:179-87. https://doi.org/10.1002/ijc.10926.

67. Li X, Lin Y, Yang X, Wu X, He X. Long noncoding RNA H19 regulates EZH2 expression by interacting with miR-630 and promotes cell invasion in nasopharyngeal carcinoma. Biochemical and Biophysical Research Communications. 2016; 473:913-9. http://doi.org/10.1016/j.bbrc.2016.03.150.

68. Gutschner T, Hämmerle M, Eissmann M, Hsu J, Kim Y, Hung G, Revenko A, Arun G, Stentrup M, Gross M, Zörnig M, MacLeod AR, Spector DL, et al. The noncoding RNA MALAT1 is a critical regulator of the metastasis phenotype of lung cancer cells. Cancer research. 2013; 73:1180-9. https://doi.org/10.1158/0008-5472.can-12-2850.

69. Wang J, Su L, Chen X, Li P, Cai Q, Yu B, Liu B, Wu $\mathrm{W}$, Zhu Z. MALAT1 promotes cell proliferation in gastric cancer by recruiting SF2/ASF. Biomedicine \& Pharmacotherapy. 2014; 68:557-64. http://doi. org/10.1016/j.biopha.2014.04.007.

70. Fan Y, Shen B, Tan M, Mu X, Qin Y, Zhang F, Liu Y. TGF$\beta$-induced upregulation of malat1 promotes bladder cancer metastasis by associating with suz12. Clin Cancer Res. 2014; 20:1531-41. https://doi.org/10.1158/1078-0432.ccr-13-1455.

71. Zhang R, Hardin H, Wei H, Chen J, Asioli S, Righi A, Maletta F, Sapino A, Lloyd RV. MALAT1 Long Non-coding RNA Expression in Thyroid Tissues: Analysis by In Situ Hybridization and Real-Time PCR. Endocrine Pathology. 2016: 1-6.

72. Jin C, Yan B, Lu Q, Lin Y, Ma L. The role of MALAT1/ $\mathrm{miR}-1 /$ slug axis on radioresistance in nasopharyngeal carcinoma. Tumor Biology. 2016; 37:4025-33.

73. Zhang TH, Liang LZ, Liu XL, Wu JN, Su K, Chen JY, Zheng QY, Huang HZ, Liao GQ. Long non-coding RNA MALAT1 interacts with miR-124 and modulates tongue cancer growth by targeting JAG1. Oncology Reports. 2017; $37: 2087$.

74. Liang J, Liang L, Ouyang K, Li Z, Yi X. MALAT1 induces tongue cancer cells' EMT and inhibits apoptosis through
Wnt/B-catenin signaling pathway. Journal of Oral Pathology \& Medicine. 2016; 46:98.

75. Fang Z, Zhang S, Wang Y, Shen S, Wang F, Hao Y, Li Y, Zhang B, Zhou Y, Yang H. Long non-coding RNA MALAT-1 modulates metastatic potential of tongue squamous cell carcinomas partially through the regulation of small proline rich proteins. BMC Cancer. 2016; 16:706.

76. Huang JK, Ma L, Song WH, Lu BY, Huang YB, Dong HM, Ma XK, Zhu ZZ, Zhou R. MALAT1 promotes the proliferation and invasion of thyroid cancer cells via regulating the expression of IQGAP1. Biomedicine \& Pharmacotherapy. 2016; 83:1-7.

77. Feng J, Tian L, Sun Y, Li D, Wu T, Wang Y, Liu M. Expression of long non-coding ribonucleic acid metastasisassociated lung adenocarcinoma transcript-1 is correlated with progress and apoptosis of laryngeal squamous cell carcinoma. Head Neck Oncol. 2012; 4:46.

78. Xie L, Hu Z, Wang X, Li Z. [Expression of long noncoding RNA MALAT1 gene in human nasopharyngeal carcinoma cell lines and its biological significance]. [Article in Chinese]. Nan Fang Yi Ke Da Xue Xue Bao. 2013; 33:692-7.

79. Xuan Z, Su L, Cai G, Kong L, Zhang T, Yu R, Wu Y, Mei M, Lun Z, Wang X. Long Non Coding RNA MALAT1 Promotes Tumor Growth and Metastasis by inducing Epithelial-Mesenchymal Transition in Oral Squamous Cell Carcinoma. Scientific Reports. 2015; 5:15972.

80. Yoshimoto R, Mayeda A, Yoshida M, Nakagawa S. MALAT1 long non-coding RNA in cancer. Biochimica Et Biophysica Acta. 2015; 1859:192-9.

81. Ji Q, Liu X, Fu X, Zhang L, Sui H, Zhou L, Sun J, Cai J, Qin J, Ren J. Resveratrol inhibits invasion and metastasis of colorectal cancer cells via MALAT1 mediated Wnt/ $\beta$ catenin signal pathway. Plos One. 2013; 8:e78700.

82. Yap KL, Li S, Muñozcabello AM, Raguz S, Zeng L, Mujtaba S, Gil J, Walsh MJ, Zhou MM. Molecular Interplay of the Non-coding RNA ANRIL and Methylated Histone H3 Lysine 27 by Polycomb CBX7 in Transcriptional Silencing of INK4a. Molecular Cell. 2010; 38:662-74.

83. Zou ZW, Ma C, Medoro L, Chen L, Wang B, Gupta R, Liu T, Yang XZ, Chen TT, Wang RZ. LncRNA ANRIL is upregulated in nasopharyngeal carcinoma and promotes the cancer progression via increasing proliferation, reprograming cell glucose metabolism and inducing side-population stemlike cancer cells. Oncotarget. 2011; 31:61741-54. https://doi. org/10.18632/oncotarget.11437.

84. Wang Y, Cheng N, Luo J. Downregulation of lncRNA ANRIL represses tumorigenicity and enhances cisplatininduced cytotoxicity via regulating microRNA let-7a in nasopharyngeal carcinoma. Journal of Biochemical \& Molecular Toxicology. 2017.

85. Pan Y, Li C, Chen J, Zhang K, Chu X, Wang R, Chen L. The Emerging Roles of Long Noncoding RNA ROR (lincRNA-ROR) and its Possible Mechanisms in Human Cancers. Cellular Physiology \& Biochemistry International 
Journal of Experimental Cellular Physiology Biochemistry \& Pharmacology. 2016; 40:219.

86. Li L, Gu M, You B, Shi S, Shan Y, Bao L, You Y. Long non-coding RNA ROR promotes proliferation, migration and chemoresistance of nasopharyngeal carcinoma. Cancer Science. 2016; 107:1215.

87. Singh A, Settleman J. Singh A, Settleman J. EMT, cancer stem cells and drug resistance: an emerging axis of evil in the war on cancer. Oncogene. 2010; 29:4741-4751.

88. Zhang HY, Feng L, Zhang JW, Fei W, Li W, Kang XG. Effects of long noncoding RNA-ROR on tamoxifen resistance of breast cancer cells by regulating microRNA-205. Cancer Chemotherapy \& Pharmacology. 2017; 79:327-37.

89. Bo H, Gong Z, Zhang W, Li X, Zeng Y, Liao Q, Chen P, Shi L, Lian Y, Jing Y. Upregulated long non-coding RNA AFAP1-AS1 expression is associated with progression and poor prognosis of nasopharyngeal carcinoma. Oncotarget. 2015; 6:20404-18. https://doi.org/10.18632/oncotarget.4057.

90. Zeng Z, Bo H, Gong Z, Lian Y, Li X, Li X, Zhang W, Deng H, Zhou M, Peng S. AFAP1-AS1, a long noncoding RNA upregulated in lung cancer and promotes invasion and metastasis. Tumor Biology. 2016; 37:729.

91. Zhang JY, Weng MZ, Song FB, Xu YG, Liu Q, Wu JY, Qin J, Jin T, Xu JM. Long noncoding RNA AFAP1-AS1 indicates a poor prognosis of hepatocellular carcinoma and promotes cell proliferation and invasion via upregulation of the RhoA/Rac2 signaling. International Journal of Oncology. 2016; 48:1590.

92. Sun Q, Liu H, Li L, Zhang S, Liu K, Liu Y, Yang C. Long noncoding RNA-LET, which is repressed by EZH2, inhibits cell proliferation and induces apoptosis of nasopharyngeal carcinoma cell. Medical Oncology. 2015; 32:673.

93. Guo J, Ma J, Zhao G, Li G, Fu Y, Luo Y. Long NonCoding RNA LINC0086 Functions as a Tumor Suppressor in Nasopharyngeal Carcinoma By Targeting miR-214. Oncology Research. 2017; 25:1189-1197.

94. Gong Z, Zhang S, Zeng Z, Wu H, Yang Q, Xiong F, Shi L, Yang J, Zhang W, Zhou Y. LOC401317, a p53-regulated long non-coding RNA, inhibits cell proliferation and induces apoptosis in the nasopharyngeal carcinoma cell line HNE2. Plos One. 2014; 9:e110674.

95. Chua MLK, Wee JTS, Hui EP, Chan ATC. Nasopharyngeal carcinoma. The Lancet. 2016; 387:1012-24. https://doi. org/10.1016/S0140-6736(15)00055-0.

96. Zhang W, Huang C, Gong Z, Zhao Y, Tang K, Li X, Fan S, Shi L, Li X, Zhang P. Expression of LINC00312, a long intergenic non-coding RNA, is negatively correlated with tumor size but positively correlated with lymph node metastasis in nasopharyngeal carcinoma. Journal of Molecular Histology. 2013; 44:545-54.

97. Ren S, Li G, Liu C, Cai T, Su Z, Wei M, She L, Tian Y, Qiu Y, Zhang X. Next generation deep sequencing identified a novel lncRNA n375709 associated with paclitaxel resistance in nasopharyngeal carcinoma. Oncology Reports. 2016; 36:1861.

98. Wang Y, Guo Q, Zhao Y, Chen J, Wang S, Jun HU, Sun Y. BRAF-activated long non-coding RNA contributes to cell proliferation and activates autophagy in papillary thyroid carcinoma. Oncology Letters. 2014; 8:1947.

99. Zheng H, Meng W, Jiang L, Chu H, Hu J, Ning J, Li B, Dong W, Jie X. BRAF-Activated Long Noncoding RNA Modulates Papillary Thyroid Carcinoma Cell Proliferation through Regulating Thyroid Stimulating Hormone Receptor. Cancer Research \& Treatment. 2016; 48:698.

100. Liao T, Qu N, Shi RL, Guo K, Ma B, Cao YM, Xiang J, Lu ZW, Zhu YX, Li DS. BRAF-activated LncRNA functions as a tumor suppressor in papillary thyroid cancer. Oncotarget. 2016; 8:238-247. https://doi.org/10.18632/ oncotarget.10825.

101. Li R, Zhang L, Jia L, Duan Y, Li Y, Bao L, Sha N. Long Non-Coding RNA BANCR Promotes Proliferation in Malignant Melanoma by Regulating MAPK Pathway Activation. Plos One. 2014; 9:e100893.

102. Jiang W, Zhang D, Xu B, Wu Z, Liu S, Zhang L, Tian Y, Han X, Tian D. Long non-coding RNA BANCR promotes proliferation and migration of lung carcinoma via MAPK pathways. Biomedecine Pharmacotherapy. 2015; 69:90-5.

103. He H, Li W, Liyanarachchi S, Jendrzejewski J, Srinivas M, Davuluri RV, Nagy R, De la Chapelle A. Genetic Predisposition to Papillary Thyroid Carcinoma: Involvement of FOXE1, TSHR, and a Novel lincRNA Gene, PTCSC2. Journal of Clinical Endocrinology \& Metabolism. 2014; 100:jc20142147.

104. Jendrzejewski J, He H, Radomska HS, Li W, Tomsic J, Liyanarachchi S, Davuluri RV, Nagy R, De la Chapelle A. The polymorphism rs944289 predisposes to papillary thyroid carcinoma through a large intergenic noncoding RNA gene of tumor suppressor type. Proceedings of the National Academy of Sciences of the United States of America. 2012; 109:8646.

105. Wang Y, He H, Li W, Phay J, Shen R, Yu L, Hancioglu B, De la Chapelle A. MYH9 binds to lncRNA gene PTCSC2 and regulates FOXE1 in the 9q22 thyroid cancer risk locus. Proceedings of the National Academy of Sciences of the United States of America. 2017; 114:474-479.

106. Fan M, Xinying LI, Jiang W, Huang Y, Jingdong LI, Wang Z. A long non-coding RNA, PTCSC3, as a tumor suppressor and a target of miRNAs in thyroid cancer cells. Experimental \& Therapeutic Medicine. 2013; 5:1143.

107. Carramusa L, Contino F, Ferro A, Minafra L, Perconti G, Giallongo A, Feo S. The PVT-1 oncogene is a Myc protein target that is overexpressed in transformed cells. Journal of Cellular Physiology. 2007; 213:511-8.

108. Zhou Q, Chen J, Feng J, Wang J. Long noncoding RNA PVT1 modulates thyroid cancer cell proliferation by 
recruiting $\mathrm{EZH} 2$ and regulating thyroid-stimulating hormone receptor (TSHR). Tumor Biology. 2016; 37:3105

109. Sasaki YT, Ideue T, Sano M, Mituyama T, Hirose T. $\mathrm{MEN} \varepsilon / \beta$ noncoding RNAs are essential for structural integrity of nuclear paraspeckles. Proceedings of the National Academy of Sciences of the United States of America. 2009; 106:2525-30.

110. Clemson CM, Hutchinson JN, Sara SA, Ensminger AW, Fox AH, Chess A, Lawrence BJ. An Architectural Role for a Nuclear Noncoding RNA: RNA Is Essential for the Structure of Paraspeckles. Molecular Cell. 2009; 33:717.

111. Chakravarty D, Sboner A, Nair SS, Giannopoulou E, Li R, Hennig S, Mosquera JM, Pauwels J, Park K, Kossai M. The oestrogen receptor alpha-regulated lncRNA NEAT1 is a critical modulator of prostate cancer. Nature Communications. 2011; 5:5383.

112. Guo S, Chen W, Luo Y, Ren F, Zhong T, Rong M, Dang Y, Feng Z, Chen G. Clinical implication of long non-coding RNA NEAT1 expression in hepatocellular carcinoma patients. International Journal of Clinical \& Experimental Pathology. 2015; 8:5395.

113. Zhen L, Yun-Hui L, Hong-Yu D, Jun M, Yi-Long Y. Long noncoding RNA NEAT1 promotes glioma pathogenesis by regulating miR-449b-5p/c-Met axis. Tumor Biology. 2016; $37: 673$.

114. Chen X, Kong J, Ma Z, Gao S, Feng X. Up regulation of the long non-coding RNA NEAT1 promotes esophageal squamous cell carcinoma cell progression and correlates with poor prognosis. American Journal of Cancer Research. 2015; 5:2808.

115. Li JH, Zhang SQ, Qiu XG, Zhang SJ, Zheng SH, Zhang DH. Long non-coding RNA NEAT1 promotes malignant progression of thyroid carcinoma by regulating miRNA-214. Int J Oncol. 2017; 50:708-16. https://doi. org/10.3892/ijo.2016.3803.

116. Hu X, Feng Y, Zhang D, Zhao SD, Hu Z, Greshock J, Zhang Y, Yang L, Zhong X, Wang LP, Jean S, Li C, Huang Q, et al. A Functional Genomic Approach Identifies FAL1 as an Oncogenic Long Noncoding RNA that Associates with BMI1 and Represses p21 Expression in Cancer. Cancer Cell. 2014; 26:344-57.

117. Jeong S, Lee J, Kim D, Seol MY, Lee WK, Jeong JJ, Nam KH, Jung SG, Shin DY, Lee EJ, Chung WY, Jo YS. Relationship of Focally Amplified Long Noncoding on Chromosome 1 (FAL1) lncRNA with E2F Transcription Factors in Thyroid Cancer. Medicine (Baltimore). 2016; 95:e2592. https://doi.org/10.1097/ md.0000000000002592.

118. Pan W, Zhou L, Ge M, Zhang B, Yang X, Xiong X, Fu G, Zhang J, Nie X, Li H. Whole exome sequencing identifies lncRNA GAS8-AS1 and LPAR4 as novel papillary thyroid carcinoma driver alternations. Human Molecular Genetics. $2016 ; 25: 1875$.
119. Yoon H, He H, Nagy R, Davuluri R, Suster S, Schoenberg D, Pellegata N, Chapelle AL. Identification of a novel noncoding RNA gene, NAMA, that is downregulated in papillary thyroid carcinoma with BRAF mutation and associated with growth arrest. International Journal of Cancer. 2007; 121:767-75.

120. Goodall J, Wellbrock C, Dexter TJ, Roberts K, Marais R, Goding CR. The Brn-2 Transcription Factor Links Activated BRAF to Melanoma Proliferation. Molecular \& Cellular Biology. 2004; 24:2923.

121. Zhang Y, Yu S, Jiang L, Wang X, Song X. HOTAIR is a promising novel biomarker in patients with thyroid cancer. Exp Ther Med. 2017; 13:2274-8. https://doi.org/10.3892/ etm.2017.4231.

122. Zhu H, Lv Z, An C, Shi M, Pan W, Zhou L, Yang W, Yang M. Onco-lncRNA HOTAIR and its functional genetic variants in papillary thyroid carcinoma. Scientific Reports. 2016; 6:31969. https://doi.org/10.1038/srep31969.

123. Davies L, Welch H. Current thyroid cancer trends in the united states. JAMA Otolaryngology-Head \& Neck Surgery. 2014; 140:317-22. https://doi.org/10.1001/ jamaoto.2014.1.

124. Boi F, Pani F, Mariotti S. Thyroid Autoimmunity and Thyroid Cancer: Review Focused on Cytological Studies. European Thyroid Journal. 2017; 6:178-86.

125. Xia S, Wang C, Ni X, Ni Z, Dong Y, Zhan W. NONHSAT076754 aids ultrasonography in predicting lymph node metastasis and promotes migration and invasion of papillary thyroid cancer cells. Oncotarget. 2016; 8:2293-2306. https://doi.org/10.18632/oncotarget.13725.

126. Li JH, Zhang SQ, Qiu XG, Zhang SJ, Zheng SH, Zhang DH. Long non-coding RNA NEAT1 promotes malignant progression of thyroid carcinoma by regulating miRNA-214. International Journal of Oncology. 2016; 50: 708-716.

127. Kim D, Lee WK, Jeong S, Seol MY, Kim H, Kim KS, Lee EJ, Lee J, Jo YS. Upregulation of long noncoding RNA LOC100507661 promotes tumor aggressiveness in thyroid cancer. Molecular \& Cellular Endocrinology. 2016; 431:36-45.

128. Ribeiro C, Correia V, Martins P, Gama FM, LancerosMendez S. Proving the suitability of magnetoelectric stimuli for tissue engineering applications. Colloid Surface B. 2016; 140:430-6. https://doi.org/10.1016/j.colsurfb.2015.12.055.

129. Liu S, Song L, Zeng S, Liang Z. MALAT1-miR-124-RBG2 axis is involved in growth and invasion of HR-HPV-positive cervical cancer cells. Tumor Biology. 2016; 37:633.

130. Feng T, Fang S, Wu Q, Zhang X, Xu D, Qian K, Xie Y, Wang S, Xu N, Wang Y. miR-124 downregulation leads to breast cancer progression via LncRNA-MALAT1 regulation and CDK4/E2F1 signal activation. Oncotarget. 2016; 7:16205-16216. https://doi.org/10.18632/oncotarget.7578.

131. Sun L, Li Y, Yang B. Downregulated long non-coding RNA MEG3 in breast cancer regulates proliferation, migration and invasion by depending on p53's transcriptional activity. 
Biochemical \& Biophysical Research Communications. 2016; 478:323-9.

132. Chen RP, Huang ZL, Liu LX, Xiang MQ, Li GP, Feng JL, Liu B, Wu LF. Involvement of endoplasmic reticulum stress and p53 in lncRNA MEG3-induced human hepatoma HepG2 cell apoptosis. Oncology Reports. 2016; 36:1649.

133. Jia LF, Wei SB, Gan YH, Guo Y, Gong K, Mitchelson K, Cheng J, Yu GY. Expression, regulation and roles of miR-26a and MEG3 in tongue squamous cell carcinoma. International Journal of Cancer. 2014; 135:2282-93.

134. Zhou Y, Zhang X, Klibanski A. MEG3 noncoding RNA: a tumor suppressor. Journal of Molecular Endocrinology. 2012; 48:R45-53.

135. Li Y, Ren M, Zhao Y, Lu X, Wang M, Hu J, Lu G, He S. MicroRNA-26a inhibits proliferation and metastasis of human hepatocellular carcinoma by regulating DNMT3BMEG3 axis. Oncology Reports. 2017; 37: 3527-3535.

136. Huang W, Cui X, Chen J, Feng Y, Song E, Li J, Liu Y. Long non-coding RNA NKILA inhibits migration and invasion of tongue squamous cell carcinoma cells via suppressing epithelial-mesenchymal transition. Oncotarget. 2016; 7:62520. https://doi.org/10.18632/oncotarget.11528.

137. Chaturvedi MM, Sung B, Yadav VR, Kannappan R, Aggarwal BB. NF- $\kappa \mathrm{B}$ addiction and its role in cancer: 'one size does not fit all'. Oncogene. 2011; 30:1615.

138. Dhamija S, Diederichs S. From junk to master regulators of invasion: lncRNA functions in migration, EMT and metastasis. International Journal of Cancer. 2016; 139:269-80.

139. Liu B, Sun L, Liu Q, Gong C, Yao Y, Lv X, Lin L, Yao

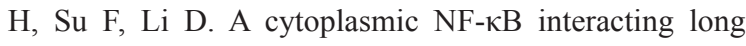
noncoding RNA blocks IкB phosphorylation and suppresses breast cancer metastasis. Cancer Cell. 2015; 27:370.

140. Bian D, Gao C, Bao K, Song G. The long non-coding RNA NKILA inhibits the invasion-metastasis cascade of malignant melanoma via the regulation of NF-KB. American Journal of Cancer Research. 2017; 7:28.

141. Fang Z, Wu L, Wang L, Yang Y, Meng Y, Yang H. Increased expression of the long non-coding RNA UCA1 in tongue squamous cell carcinomas: a possible correlation with cancer metastasis. Oral Surgery Oral Medicine Oral Pathology \& Oral Radiology. 2014; 117:89-95.

142. Yu J, Liu Y, Gong Z, Zhang S, Guo C, Li X, Tang Y, Yang L, He Y, Wei F. Overexpression long non-coding RNA LINC00673 is associated with poor prognosis and promotes invasion and metastasis in tongue squamous cell carcinoma. Oncotarget. 2016; 8:16621-16632. https://doi.org/10.18632/ oncotarget. 14200 .

143. Majchrzak E, Szybiak B, Wegner A, Pienkowski P, Pazdrowski J, Luczewski L, Sowka M, Golusinski P, Malicki J, Golusinski W. Oral cavity and oropharyngeal squamous cell carcinoma in young adults: a review of the literature. Radiology and Oncology. 2014; 48:1-10.

144. Almangush A, Heikkinen I, Makitie AA, Coletta RD, Laara E, Leivo I, Salo T. Prognostic biomarkers for oral tongue squamous cell carcinoma: a systematic review and metaanalysis. Br J Cancer. 2017; 117:856-866. https://doi. org/10.1038/bjc.2017.244.

145. Yu J, Liu Y, Guo C, Zhang S, Gong Z, Tang Y, Yang L, He Y, Lian Y, Li X. Upregulated long non-coding RNA LINC00152 expression is associated with progression and poor prognosis of tongue squamous cell carcinoma. Journal of Cancer. 2017; 8:523.

146. Zhang H, Zhao L, Wang YX, Xi M, Liu SL, Luo LL. Long non-coding RNA HOTTIP is correlated with progression and prognosis in tongue squamous cell carcinoma. Tumor Biology. 2015; 36:8805-9.

147. Tsai MC, Manor O, Wan Y, Mosammaparast N, Wang JK, Lan F, Shi Y, Segal E, Chang HY. Long noncoding RNA as modular scaffold of histone modification complexes. Science (New York, NY). 2010; 329:689-93. https://doi. org/10.1126/science.1192002.

148. Wu J, Xie H. Expression of long noncoding RNA-HOX transcript antisense intergenic RNA in oral squamous cell carcinoma and effect on cell growth. Tumor Biology. 2015; 36:8573-8. https://doi.org/10.1007/s13277-015-3598-5.

149. Wu Y, Zhang L, Zhang L, Wang Y, Li H, Ren X, Wei F, Yu W, Liu T, Wang X, Zhou X, Yu J, Hau X. Long noncoding RNA HOTAIR promotes tumor cell invasion and metastasis by recruiting EZH2 and repressing E-cadherin in oral squamous cell carcinoma. International Journal of Oncology. 2015; 46:2586-94. https://doi.org/10.3892/ ijo.2015.2976.

150. Gao L, Ren W, Zhang L, Li S, Kong X, Zhang H, Dong J, Cai G, Jin C, Zheng D. PTENp1, a natural sponge of miR-21, mediates PTEN expression to inhibit the proliferation of oral squamous cell carcinoma. Molecular Carcinogenesis. 2016; 56.

151. Blanco-Aparicio C, Renner O, Leal JF, Carnero A. PTEN, more than the AKT pathway. Carcinogenesis. 2007; 28:1379.

152. Yang YT, Wang YF, Lai JY, Shen SY, Wang F, Kong J, Zhang W, Yang HY. Long non-coding RNA UCA1 contributes to the progression of oral squamous cell carcinoma by regulating the $\mathrm{WNT} / \beta$-catenin signaling pathway. Cancer Science. 2016; 107:1581.

153. Xiao $\mathrm{C}, \mathrm{Wu} \mathrm{CH}, \mathrm{Hu} \mathrm{HZ}$. LncRNA UCA1 promotes epithelial-mesenchymal transition (EMT) of breast cancer cells via enhancing Wnt/beta-catenin signaling pathway. European Review for Medical \& Pharmacological Sciences. 2016; 20:2819.

154. Liu H, Wang G, Yang L, Qu J, Yang Z, Zhou X. Knockdown of Long Non-Coding RNA UCA1 Increases the Tamoxifen Sensitivity of Breast Cancer Cells through Inhibition of Wnt/ß-Catenin Pathway. Plos One. 2016; 11:e168406.

155. Shang C, Guo Y, Zhang J, Huang B. Silence of long noncoding RNA UCA1 inhibits malignant proliferation and chemotherapy resistance to adriamycin in gastric cancer. Cancer Chemotherapy and Pharmacology. 2016; 77:1061. 
156. Liu J, Shen L, Yao J, Li Y, Wang Y, Chen H, Geng P. Forkhead box $\mathrm{C} 1$ promoter upstream transcript, a novel long non-coding RNA, regulates proliferation and migration in basal-like breast cancer. Molecular Medicine Reports. 2014; 11:3155-9.

157. Kong X, Yao J, Luo W, Feng F, Ma J, Ren Y, Wang D, Bu $\mathrm{R}$. The expression and functional role of a FOXC1 related mRNA-lncRNA pair in oral squamous cell carcinoma. Molecular and Cellular Biochemistry. 2014; 394:177.

158. Xia L, Huang W, Tian D, Zhu H, Qi X, Chen Z, Zhang Y, $\mathrm{Hu}$ H, Fan D, Nie Y. Overexpression of forkhead box C1 promotes tumor metastasis and indicates poor prognosis in hepatocellular carcinoma. Hepatology. 2013; 57:610-24.

159. Zhang S, Tian L, Ma P, Sun Q, Zhang K, GuanchaoWang, Liu $\mathrm{H}, \mathrm{Xu} \mathrm{B}$. Potential role of differentially expressed IncRNAs in the pathogenesis of oral squamous cell carcinoma. Archives of Oral Biology. 2015; 60:1581-7.

160. Zhang CZ. Long non-coding RNA FTH1P3 facilitates oral squamous cell carcinoma progression by acting as a molecular sponge of miR-224-5p to modulate fizzled 5 expression. Gene. 2017; 607:47-55.

161. Liu F, Liu Y, Shen J, Zhang G, Han J. MicroRNA-224 inhibits proliferation and migration of breast cancer cells by down-regulating fizzled 5 expression. Oncotarget. 2016; 7:49130-42. https://doi.org/10.18632/oncotarget.9734.

162. Shuang L, Zhang S, Peng W, Chao Y, Chen S, Yang J, Wang J. LncRNA, TUG1 regulates the oral squamous cell carcinoma progression possibly via interacting with $\mathrm{Wnt} / \beta$ catenin signaling. Gene. 2017; 608:49-57.

163. Seki S, Fujiwara M, Matsuura M, Fujita S, Ikeda H, Asahina I, Ikeda T. Prediction of outcome of patients with oral squamous cell carcinoma using vascular invasion and the strongly positive expression of vascular endothelial growth factors. Oral Oncol. 2011; 47:588-93. https://doi. org/10.1016/j.oraloncology.2011.04.013.

164. Tang JY, Hsi E, Huang YC, Hsu NC, Chu PY, Chai CY. High LC3 expression correlates with poor survival in patients with oral squamous cell carcinoma. Hum Pathol. 2013; 44:2558-62. https://doi.org/10.1016/j. humpath.2013.06.017.

165. Hamada T, Wakamatsu T, Miyahara M, Nagata S, Nomura M, Kamikawa Y, Yamada N, Batra SK, Yonezawa S, Sugihara K. MUC4: a novel prognostic factor of oral squamous cell carcinoma. Int J Cancer. 2012; 130:1768-76. https://doi.org/10.1002/ijc.26187.

166. Morandi L, Gissi D, Tarsitano A, Asioli S, Monti V, Del Corso G, Marchetti C, Montebugnoli L, Foschini MP. DNA methylation analysis by bisulfite next-generation sequencing for early detection of oral squamous cell carcinoma and high-grade squamous intraepithelial lesion from oral brushing. Journal of Cranio-Maxillofacial Surgery. 2015; 43:1494-500. https://doi.org/10.1016/j.jcms.2015.07.028.

167. Zhou N, Liao W, Huang Z, Hu Z, Huang W, Wang Q. Overexpression of long non-coding RNA CCAT2 predicts a poor prognosis in patients with oral squamous cell carcinoma. Int J Clin Exp Pathol. 2016; 9:110-7.

168. Tang H, Wu Z, Zhang J, Su B. Salivary lncRNA as a potential marker for oral squamous cell carcinoma diagnosis. Mol Med Rep. 2013; 7:761-6. https://doi. org/10.3892/mmr.2012.1254.

169. Park NJ, Zhou H, Elashoff D, Henson BS, Kastratovic DA, Abemayor E, Wong DT. Salivary microRNA: Discovery, Characterization, and Clinical Utility for Oral Cancer Detection. Clin Cancer Res. 2009; 15:5473-7. https://doi. org/10.1158/1078-0432.ccr-09-0736.

170. Peng W, Wu T, Han Z, Jin Q, He G, Yu H, Xuan L, Xin W, Tian L, Sun Y. Long noncoding RNA NEAT1 promotes laryngeal squamous cell cancer through regulating miR107/CDK6 pathway. Journal of Experimental \& Clinical Cancer Research. 2016; 35:22.

171. Yang X, Xiao Z, Du X, Huang L, Du G. Silencing of the long non-coding RNA NEAT1 suppresses glioma stemlike properties through modulation of the miR-107/CDK6 pathway. Oncology Reports. 2016; 37:555-562.

172. Gao W, Zhang C, Ma T, Wen S, Fu R, Zhao D, Wu Y, Wang B. Potential biomarkers and their regulatory relationships in laryngeal squamous cell carcinoma with lymph node metastasis revealed by integrating mRNA, microRNA and long non-coding RNA profiles. Int J Clin Exp Pathol. 2016; 9:5103-16.

173. Kaneko S, Li G, Son J, Xu CF, Margueron R, Neubert TA, Reinberg D. Phosphorylation of the PRC2 component Ezh2 is cell cycle-regulated and up-regulates its binding to ncRNA. Genes Dev. 2010; 24:2615-20. https://doi. org/10.1101/gad.1983810.

174. Li D, Feng J, Wu T, Wang Y, Sun Y, Ren J, Liu M. Long Intergenic Noncoding RNA HOTAIR Is Overexpressed and Regulates PTEN Methylation in Laryngeal Squamous Cell Carcinoma. The American Journal of Pathology. 2013; 182:64-70. http://doi.org/10.1016/j.ajpath.2012.08.042.

175. Zheng J, Xiao X, Wu C, Huang J, Zhang Y, Xie M, Zhang M, Zhou L. The role of long non-coding RNA HOTAIR in the progression and development of laryngeal squamous cell carcinoma interacting with EZH2. Acta Oto-Laryngologica. 2017; 137:90-8. https://doi.org/10.1080/00016489.2016.12 14982.

176. Stambolic V, Suzuki A, de la Pompa JL, Brothers GM, Mirtsos C, Sasaki T, Ruland J, Penninger JM, Siderovski DP, Mak TW. Negative Regulation of PKB/Akt-Dependent Cell Survival by the Tumor Suppressor PTEN. Cell. 1998; 95:29-39. http://doi.org/10.1016/S0092-8674(00)81780-8.

177. Wu T, Qu L, He G, Tian L, Li L, Zhou H, Jin Q, Ren J, Wang Y, Wang J, Kan X, Liu M, Shen J, et al. Regulation of laryngeal squamous cell cancer progression by the lncRNA H19/miR-148a-3p/DNMT1 axis. Oncotarget. 2016; 7:11553-66. https://doi.org/10.18632/oncotarget.7270.

178. Wolf GT, Fisher SG, Hong WK, Hillman R, Spaulding M, Laramore GE, Endicott JW, McClatchey K, Henderson WG, 
Department of Veterans Affairs Laryngeal Cancer Study Group. Induction chemotherapy plus radiation compared with surgery plus radiation in patients with advanced laryngeal cancer. The New England journal of medicine. 1991; 324:1685-90.

179. Nachalon Y, Cohen O, Alkan U, Shvero J, Popovtzer A. Characteristics and outcome of laryngeal squamous cell carcinoma in young adults. Oncol Lett. 2017; 13:1393-7. https://doi.org/10.3892/ol.2016.5528.
180. Zhou H, Zhang Z, Wu Y, Zhao J. Effect of the long noncoding RNA AC007392. 4 on growth, invasion and migration for tongue squamous cell carcinoma. Int J Clin Exp Med. 2016; 9:5805-12. 